\title{
A High-Temperature Electrochemical Carbon Monoxide Sensor with Nanostructured Metal Oxide Electrode
}

Anveeksh Koneru

West Virginia University

Follow this and additional works at: https://researchrepository.wvu.edu/etd

\section{Recommended Citation}

Koneru, Anveeksh, "A High-Temperature Electrochemical Carbon Monoxide Sensor with Nanostructured Metal Oxide Electrode" (2012). Graduate Theses, Dissertations, and Problem Reports. 3360.

https://researchrepository.wvu.edu/etd/3360

This Thesis is protected by copyright and/or related rights. It has been brought to you by the The Research Repository @ WVU with permission from the rights-holder(s). You are free to use this Thesis in any way that is permitted by the copyright and related rights legislation that applies to your use. For other uses you must obtain permission from the rights-holder(s) directly, unless additional rights are indicated by a Creative Commons license in the record and/ or on the work itself. This Thesis has been accepted for inclusion in WVU Graduate Theses, Dissertations, and Problem Reports collection by an authorized administrator of The Research Repository @ WVU. For more information, please contact researchrepository@mail.wvu.edu. 


\title{
A High-Temperature Electrochemical Carbon Monoxide Sensor with Nanostructured Metal Oxide Electrode
}

\author{
Anveeksh Koneru \\ Thesis Submitted to the \\ Benjamin M. Statler College of Engineering and Mineral Resources \\ at West Virginia University \\ in partial fulfillment of the requirements \\ for the degree of \\ Master of Science \\ in \\ Mechanical Engineering
}

Nianqiang Wu, Ph.D., (Chair and Advisor)

Hailin Li, Ph.D.

Ever J. Barbero, Ph.D.

Department of Mechanical and Aerospace Engineering

West Virginia University

Morgantown, West Virginia

April 4, 2012

Keywords: Mixed potential sensor; solid electrolyte; carbon monoxide Copyright 2012 Anveeksh Koneru 


\section{ABSTRACT \\ A High-Temperature Electrochemical Carbon Monoxide Sensor with Nanostructured Metal Oxide Electrode}

Anveeksh Koneru

Carbon monoxide (CO) is one of the major air pollutants which are emitted due to the incomplete combustion of hydrocarbon fuels. It is a colorless, odorless and tasteless gas that is highly toxic to humans and animals. Hence, a $\mathrm{CO}$ sensor not only serves as an alarm system for threat of $\mathrm{CO}$, but also be used for monitoring the combustion process to improve the combustion efficiency. The currently existing technologies to detect $\mathrm{CO}$ such as gas chromatography and optical absorption spectrometry are cumbersome, costly, and lack the capability of on-line monitoring. Thus there is a critical need for developing $\mathrm{CO}$ sensors that can give accurate and fast response to change in the concentrations of $\mathrm{CO}$ as low as $20 \mathrm{ppm}$ at high temperature (> 500 $\left.{ }^{\circ} \mathrm{C}\right)$.

In the present work, $\mathrm{La}_{0.8} \mathrm{Sr}_{0.2} \mathrm{MnO}_{3}$ (LSM) nanofibers were prepared by electrospinning method and utilized as a mixed potential sensor electrode for sensing $\mathrm{CO}$ at high temperature. The nanofibers show good thermal stability even after heat treatment at $1050{ }^{\circ} \mathrm{C}$. This nano-fibrous structure possesses several advantages such as high porosity, high surface to volume ratio and high activity towards $\mathrm{CO}$ electrochemical oxidation. The nanofibers bring improved sensitivity and lower the limit of detection as compared with bulk LSM powders. Electrochemical impedance (EIS) analysis indicated that the nano-fibrous electrode shows better charge transfer capability, leading to improved catalytic activity for $\mathrm{CO}$ oxidation and sensor performance. The developed sensor can be used for monitoring emissions from coal-fired power plants and vehicle exhausts. 


\section{Acknowledgements}

I would like to dedicate this thesis to my parents and God. Their support, love and blessings are invaluable to me. I am very grateful to my advisor Dr. Wu gave me strong motivation and inspiration to do this research.

I wholeheartedly thank Dr. Wu for teaching me science and constantly supporting me both morally and financially throughout my Masters' degree.

I sincerely thank my committee members, Dr. Hailin Li and Dr. Ever J. Barbero who spent their valuable time for assisting me.

Working in Dr. Wu's group has been a great pleasure for me. I thank each and every one of the group members for their help, support and for creating a good study atmosphere which gave me more enthusiasm to do research. Here, I would like to specially acknowledge Dr. Mingiia Zhi, post-doctoral researcher for $\mathrm{Dr}$. $\mathrm{Wu}$, who spent his valuable time for discussing key issues regarding my project. I thank him for his suggestions which were worthwhile for my research progress.

I thank all my friends who made my stay in Morgantown memorable.

Finally, I deeply thank my parents for their moral support and encouragement. 


\section{Table of Contents}

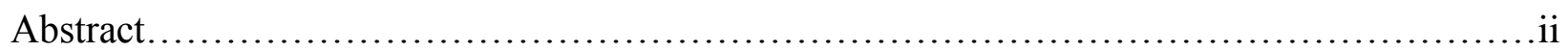

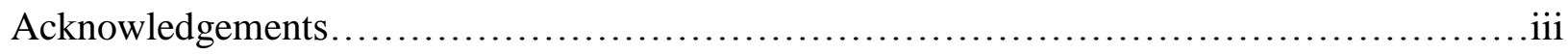

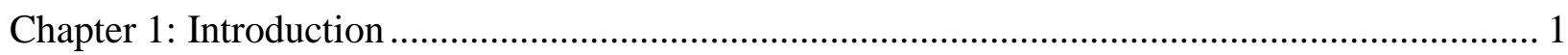



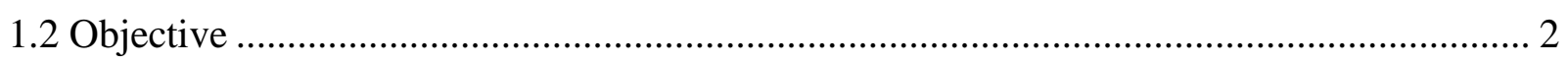

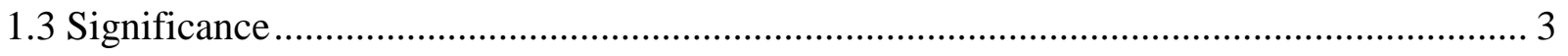



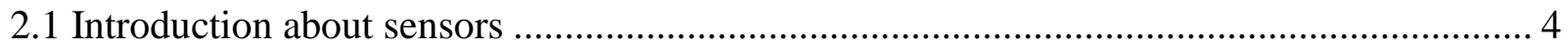

2.1.1 Classifications and basic requirements of gas sensors ......................................... 5

2.1.2 Different technologies to measure gases ................................................................ 5

2.2 Solid-Electrolyte (or solid-state) electrochemical gas sensors..................................... 10

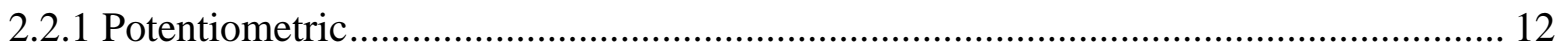

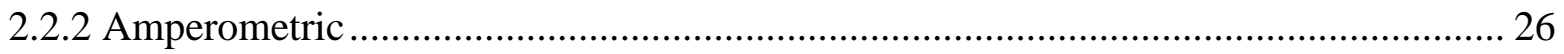

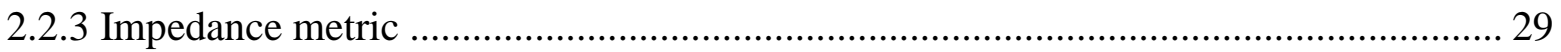

2.3 One-dimensional nanomaterials based sensors .................................................. 30

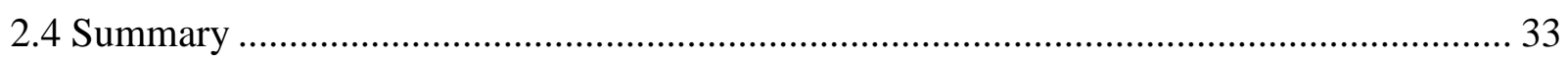

Chapter 3: Experimental Investigation of Nanofibrous $\mathrm{La}_{0.8} \mathrm{Sr}_{0.2} \mathrm{MnO}_{3}$ Electrode for Gas Sensing 34



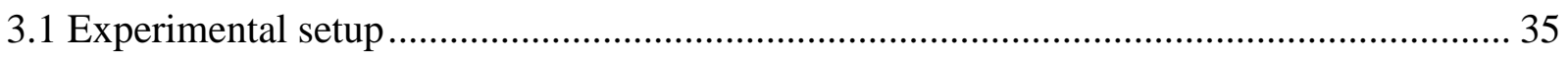

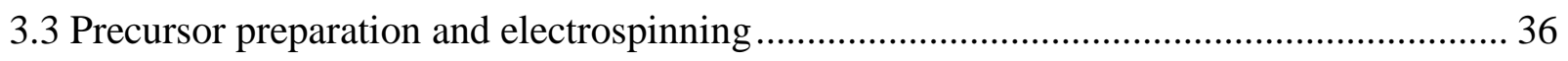

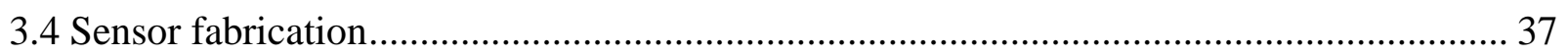



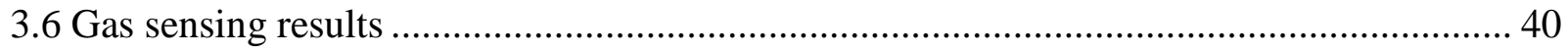

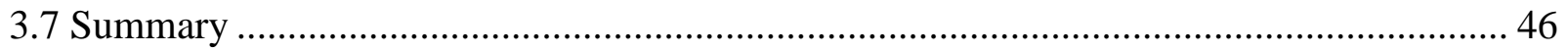

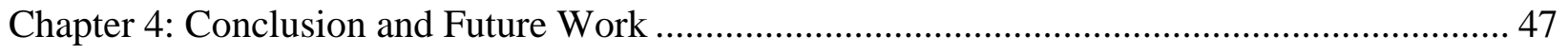

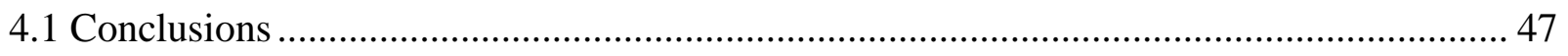



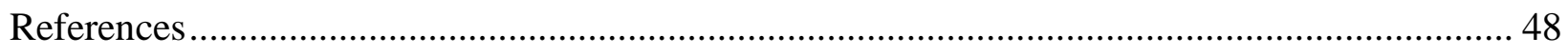




\section{List of Tables}

Table 2.1: Brief overview of different potentiometric sensors developed for various gases......31

Table 2.2: Brief overview of different amperometric sensors developed for various gases......34

Table 2.3: Brief overview of different impedancemetric sensors developed for various gases

Table 2.4 Sensor types, temperature of operation and their detection limits ..................37

Table 3.1: The fitting results of the LSM nanofibers and powders sensors in air and in $500 \mathrm{ppm}$

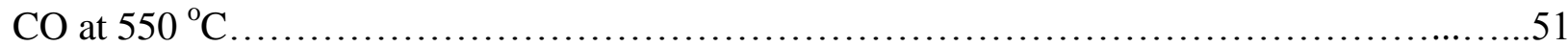




\section{List of Figures}

Figure 2.1: A representation of surface acoustic wave sensor (SAW) (13).............................. 6

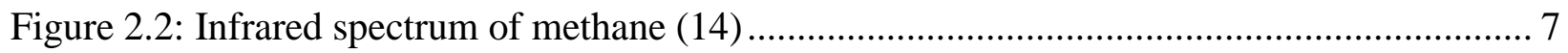

Figure 2.3: Graphical representation of semiconductor gas sensor ..................................... 8

Figure 2.4: Response to $\mathrm{Pd} / \mathrm{ZnO}$ nanorod arrays to $\mathrm{CO}$ concentration (21) ............................... 9

Figure 2.5: Band diagrams of $\mathrm{ZnO}$ nanorods when exposed to $\mathrm{CO}(21)$................................ 10

Figure 2.6: Typical structure of a tubular potentiometric device for testing gases ................... 12

Figure 2.7: Potentiometric sensor with air tight seal (38) ................................................. 13

Figure 2.8: A planar configuration of potentiometric sensors. ............................................ 14

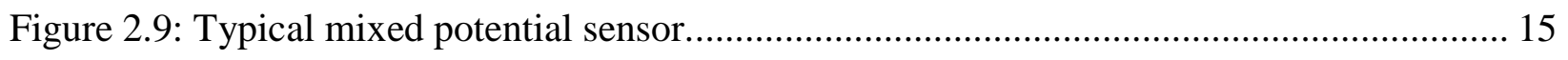

Figure: 2.10: Graphic description of ion transport and triple phase boundary (TPB) ............... 16

Figure 2.11: Polarization curve for $\mathrm{CO}$ oxidation and $\mathrm{O}_{2}$ reduction on dissimilar electrodes

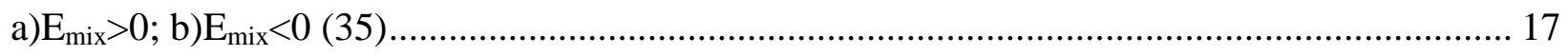

Figure 2.12: Voltage generated by the cell $\mathrm{Pt} / \mathrm{Ce}_{0.8} \mathrm{Gd}_{0.2} \mathrm{O}_{1.9} / \mathrm{Au}$ for different reducing gases (41).

Figure 2.13: Linear variation of EMF to $\ln$ (CO concentrations) of sensors with cell structure of

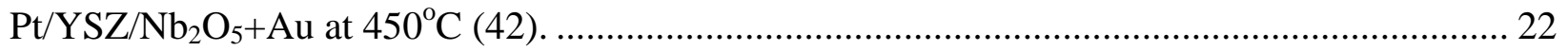

Figure 2.14: Dependencies of EMF values of pure and $\mathrm{MnO}_{2}$ containing $\mathrm{In}_{2} \mathrm{O}_{3}$ electrodes on gas

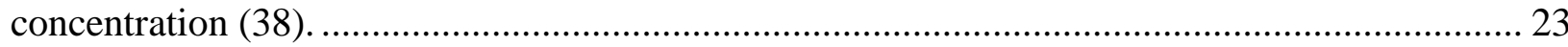

Figure 2.15: Typical structure of an amperometric sensor .............................................. 26

Figure 2.16: The response of a typical amperometric sensor (31) ......................................... 27

Figure 2.17: (a) Amperometric response to various gases and inset showing the cell configuration

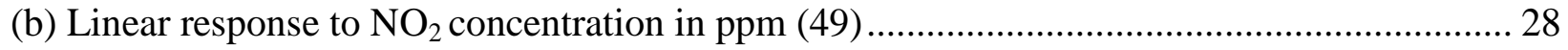

Figure 2.18: Impedance plot showing the sensor response to the presence of CO (54) ............. 29

Figure 3.1: Graphic of the testing equipment to mimic the combustion environment. ............... 35

Figure 3.2: Experimental setup for electrospinning LSM nanofibers...................................... 36

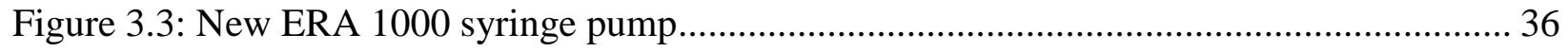

Figure 3.4: Flow chart of nanofiber preparation process ................................................... 37

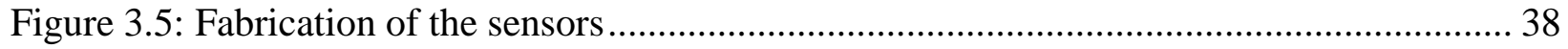

Figure 3.6: A tested sample with Pt counter electrode and $\mathrm{La}_{0.8} \mathrm{Sr}_{0.2} \mathrm{MnO}_{3}$ sensing electrode on

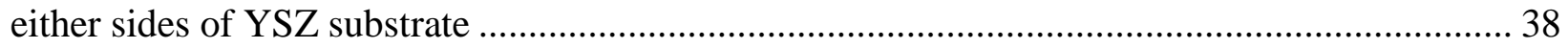


Figure 3.7: The dimensions of sensing and counter electrodes on the YSZ substrate.

Figure 3.8: (a), (b) SEM images of the LSM nanofibers sensing electrode (after sintering at 1050 ${ }^{\circ} \mathrm{C}$ for 3 hours), (c) SEM image of the LSM powder sensing electrode and (d) the XRD pattern of the LSM nanofibers after heating at $1050{ }^{\circ} \mathrm{C}$ along with standard diffraction pattern.

Figure 3.9: (a) Gas sensitivity curves of LSM nanofibers electrode; (b) Gas sensitivity curves of the LSM powders electrode; (c) Gas response curves of the nanofibers and powders electrode; (d) The linear calibration curve of the nanofibers and the powders electrode when the $\mathrm{CO}$ concentration ranged from $5 \mathrm{ppm}$ to $500 \mathrm{ppm}$................................................................. 42

Figure 3.10: (a) Comparison of the response transients to $\mathrm{CO}$ at $550{ }^{\circ} \mathrm{C}$ of the nanofibers electrode and the powder electrode, (b) is the detail response when the sensors exposed to 500

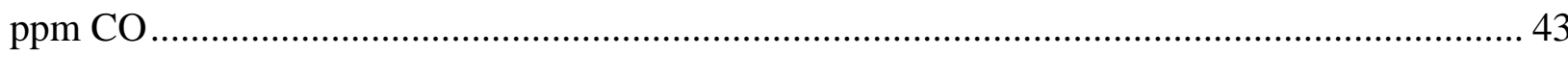

Figure 3.11: (a) Full range Nyquist Impedance spectra of the nanofibers and powders sensor taken at $550{ }^{\circ} \mathrm{C}$ at open circuit, showing the effect of the presence of $\mathrm{CO}$, the inset is the model circuit for data fitting, (b) the detail of the circle zone in (a), the number is the characterization frequency of the semicircle. The open symbols are the measured data and the solid lines are fitted data 44

Figure 3.12: Impedance Nyquist curves of the nanofiber sensor at $550{ }^{\circ} \mathrm{C}$ with $500 \mathrm{ppm} \mathrm{CO}$ taken at different DC bias .... 46 


\section{Chapter 1: Introduction}

\subsection{Background}

Emissions have become a major cause of concern in today's world and are bound to affect the human life if the present stature continues. Major contribution of emissions is from automobiles (transportation sector) and industries (power plants, refineries, manufacturing plants). Carbon monoxide $(\mathrm{CO})$ is one of the major hazardous gases which are emitted due to the incomplete combustion of organic matter due to insufficient supply of oxygen. Inhaling $\mathrm{CO}$ inhibits the oxygen carrying capacity of blood that causes myocardial ischemia (reduced oxygen to heart) which results in chest pain (angina) (1). US Environmental protection agency (EPA) has set a 1hour primary standard for human exposure to $\mathrm{CO}$ at $35 \mathrm{ppm}$ which if exceeded can cause death (2). Strict restrictions have been laid on the emissions coming from the combustion sources like automobiles, industries etc. (3). To implement them, a gas sensor capable of detecting the same is required.

For complete combustion of fossil fuels like gasoline or any other organic matter, a lean or stoichiometric amount of air is required. Stoichiometric amount is the number of moles of air (mixture of oxygen and nitrogen typically $\mathrm{O}_{2}+3.76 \mathrm{~N}_{2}$ ) required to completely burn one mole of fuel. Generally, complete combustion takes place during ideal combustion process during which only carbon dioxide, water and nitrogen are produced (4). Equation 1.1 shows a stoichiometric amount of air for one mole of fuel which generally takes place during ideal combustion process.

$$
\mathrm{C}_{\mathrm{m}} \mathrm{H}_{\mathrm{n}}+\left[\mathrm{m}+\frac{n}{4}\right] *\left[\mathrm{O} 2+3.76 \mathrm{~N}_{2}\right]=\quad \mathrm{m} * \mathrm{CO}_{2}+\frac{n}{2} \mathrm{H}_{2} \mathrm{O}+\left[\mathrm{m}+\frac{n}{4}\right] * 3.76 \mathrm{~N}_{2} \quad 1.1
$$

But, extraneous and gratuitous gases like $\mathrm{CO}$ are produced due to incomplete combustion of carbon containing fuels (organic matter) in the presence of air. For instance, burning hydrocarbons like propane in stoichiometric amounts of air would give Carbon dioxide and water (reaction given below)

$$
\mathrm{C}_{3} \mathrm{H}_{8}+\left[5^{*}\left(\mathrm{O}_{2}+3.76 \mathrm{~N}_{2}\right)\right]=3 * \mathrm{CO}_{2}+4 \mathrm{H}_{2} \mathrm{O}+5 * 3.76 \mathrm{~N}_{2} \quad 1.2
$$

5 moles of oxygen is required for complete combustion of 1 mole of propane which is shown in Equation 1.2. Now, if the same hydrocarbon is burnt in the insufficient amount of oxygen in air, the following reaction takes place. 


$$
\mathrm{C}_{3} \mathrm{H}_{8}+\left[4 *\left(\mathrm{O}_{2}+3.76 \mathrm{~N}_{2}\right)\right] \quad=\quad \mathrm{CO}_{2}+4 \mathrm{H}_{2} \mathrm{O}+2 * \mathrm{CO}+4 * 3.76 \mathrm{~N}_{2} \quad 1.3
$$

Here, when less amount of air than the required stoichiometric amount is given into the combustion chamber, carbon monoxide is released.

So, in an efficient combustion process, there will be complete conversion of hydrocarbons to carbon dioxide and water, whereas an inefficient combustion process produces incomplete combustion products like $\mathrm{CO}$. Hence, detection of $\mathrm{CO}$ by on board diagnostics would not only help in detecting the presence of $\mathrm{CO}$ but would also serve as quick monitoring of the combustion efficiency.

Hence, there is a strong need for a $\mathrm{CO}$ gas sensor that has high temperature withstanding capability, good sensing properties and compactness for application in on-board diagnostics.

\subsection{Objective}

The overall objective of this research is to develop nano-fibrous sensing electrode for mixedpotential gas sensor that is capable of detecting trace amounts of carbon monoxide effectively in harsh environments $\left(>500{ }^{\circ} \mathrm{C}\right)$. The performance of this electrode will be investigated at high temperatures. In the present work, yttria-stabilized zirconia (YSZ) is chosen as the solid electrolyte which is capable of transporting oxygen ions through it. The capability of the sensing electrode to electrochemically convert $\mathrm{CO}$ to $\mathrm{CO}_{2}$ at the triple phase boundaries (the points at which the electrode, electrolyte and gas come in contact with each other) will be investigated. Also, the influence of microstructure of the sensing electrode on the sensing performance will be studied.

The first aim is to fabricate the $\mathrm{La}_{0.8} \mathrm{Sr}_{0.2} \mathrm{MnO}_{3}$ (LSM) nanofibers which act as electrochemical catalyst in mixed-potential type $\mathrm{CO}$ sensor. These nanofibers will be fabricated through electrospinning process and later on the crystalline phase and morphology of the nanofibers will be examined.

The second aim is to fabricate a planar mixed potential type sensor with LSM nanofibers as the sensing electrode. These fabricated sensors will be tested at high temperatures $\left(>500{ }^{\circ} \mathrm{C}\right)$ to investigate their CO sensing properties. The design and fabrication procedure of the sensors will be optimized based on the results from several experiments. The obtained results will be compared to the bulk counterparts. 
Finally, the underlying mechanism for generation of mixed potential and the effect of microstructure on sensing performance will be clarified. The sensors would be characterized with SEM to find the microstructure and XRD to confirm the crystalline structure of LSM.

\subsection{Significance}

Lack of safety is consuming many lives around the world. In particular, harmful inhalations like $\mathrm{CO}$ consume more than 500 lives in United States each year (5). There were 6552 unintentional deaths recorded in a span of 10 years from the year 1979 due to motor vehicle exhaust (6). So, if a gas sensor operable at such harsh environments and having a simple design is developed, it can provide a chance to take immediate counter action to the toxic emissions by directly equipping them in on-board diagnostics and thus and saving many lives. Hence, this research can help in developing sensors that can be used for both environmental protection and combustion monitoring.

The sensors intended to fabricate in this research are equipped with nanofibrous sensing electrode which is being investigated for the first time. Through this, a correlation between the microstructure and the sensing performance can be demonstrated. 


\section{Chapter 2: Literature Survey}

\subsection{Introduction to sensors}

In general, a sensor is defined as "a device which provides a usable output in response to a specific measurand" (7). For example, for different measurands like pressure, temperature, air flow etc., there are respective sensors to detect them. Output can be in any form, typically like an electrical signal or an optical signal etc. Gas sensors are further defined as "those devices which respond to selected gases in situ and generate electric (or optical) signals dependent on their concentrations in real time" (8). Typically, gas sensors for environmental protection are designed in such a way that they produce signal sufficient enough to raise an alarm when the concentration of the leakage gases rises more than $1 / 10$ of lower exposure limit of humans.

Some general terms used in this thesis are defined below.

Limit of detection: This is the least possible concentration of the analyte that the sensor can detect. This is generally the concentration of the analyte to which the sensor's signal is three times the background noise.

Sensitivity: It is the measure of change in output of a sensor signal to a change in the input concentration of a gas.

Baseline: Baseline is the sensor output when it is exposed only to air.

Linear range: Linear range is a range of input concentrations to which the output sensor signal has a linear curve.

Response time: It is the time taken by the sensor to reach $90 \%$ of the steady state signal value from the point where it is exposed to the analyte gas

Recovery time: It is the time taken by the sensor to reach $10 \%$ of the baseline value from the point after which it is the analyte gas is turned off. 


\subsubsection{Classifications and basic requirements of gas sensors}

Gas sensors can be classified according to the

- Sensing principle employed (potentiometric, impedance-metric, piezoelectric etc.)

- Sensing materials used (Metals, oxides etc.) and

- Target gases being detected

Basic requirements of gas sensors are

- High sensitivity

- Selectivity to the analyte gas

- Stability in signal without any noise

- Repeatability in the signal for different sensor samples

- Quick response (short response time)

- Broad linear range of operation

- Low manufacturing cost

- Compatible size

- Simple analysis to analyze the signal

\subsubsection{Different technologies for gas measurements}

There is a huge demand for sensors that can effectively detect the concentrations of the analyte gas in the real-time environment. From the past 2 decades, the research on gas sensors is being done extensively to get a compatible gas sensor that can be used in-situ operations. There are various technologies like surface acoustic wave (SAW), optical sensor- IR, gas chromatography, semiconducting, solid-state electrochemical etc. to detect $\mathrm{CO}$ in air.

Each category of gas sensors stated above has specific advantages and drawbacks, constricting them for specific applications. Most of the commercially available gas detection systems like surface acoustic wave (SAW), gas chromatography, semiconducting etc. are not suitable for high temperature operations $\left(>500{ }^{\circ} \mathrm{C}\right)$. Though, research has been done in SAW type gas sensors for high temperature applications (9), the instability of sensing element at high temperatures constraints them for practical applications. 
In a typical SAW type gas sensor, two interdigited transducers are applied on a piezoelectric substrate, with a gas sensitive coating in the middle as shown in Figure 2.1. When an AC field is applied across the input transducer, an acoustic wave is propagated along the surface of the piezoelectric substrate. This produces a corresponding frequency of mechanical vibrations in it. Due to these vibrations, the output transducer generates a corresponding output AC field which serves as a sensing signal. When this substrate is exposed to the analyte gas, the gas sensitive coating (generally which is a metal oxide) adsorbs some molecules from it, resulting in an increase in the weight of the substrate. Due to this increase, the mechanical frequencies of the piezoelectric substrate produced by the input ac field are reduced, which can be measured through the corresponding AC field from the output transducer (10). Nagle et al (11); gave an equation for reduction in the frequency of vibrations $\Delta f$ (Equation 2.1) which acts as the sensing signal.

$\Delta f=\Delta f_{p} c_{v} K_{p} / \rho_{p} \quad \mathbf{2 . 1}$

Where, $\Delta f_{p}$ is the change in the frequency in the membrane, $c_{v}$ is the gas concentration, $K_{p}$ is the partition coefficient and $\rho_{p}$ is the density of the gas sensitive membrane.

These sensors typically work in room-temperature environment. The effect of vibrations in automobiles on the sensor performance and their stability to harsh exhaust environment has to be further addressed.

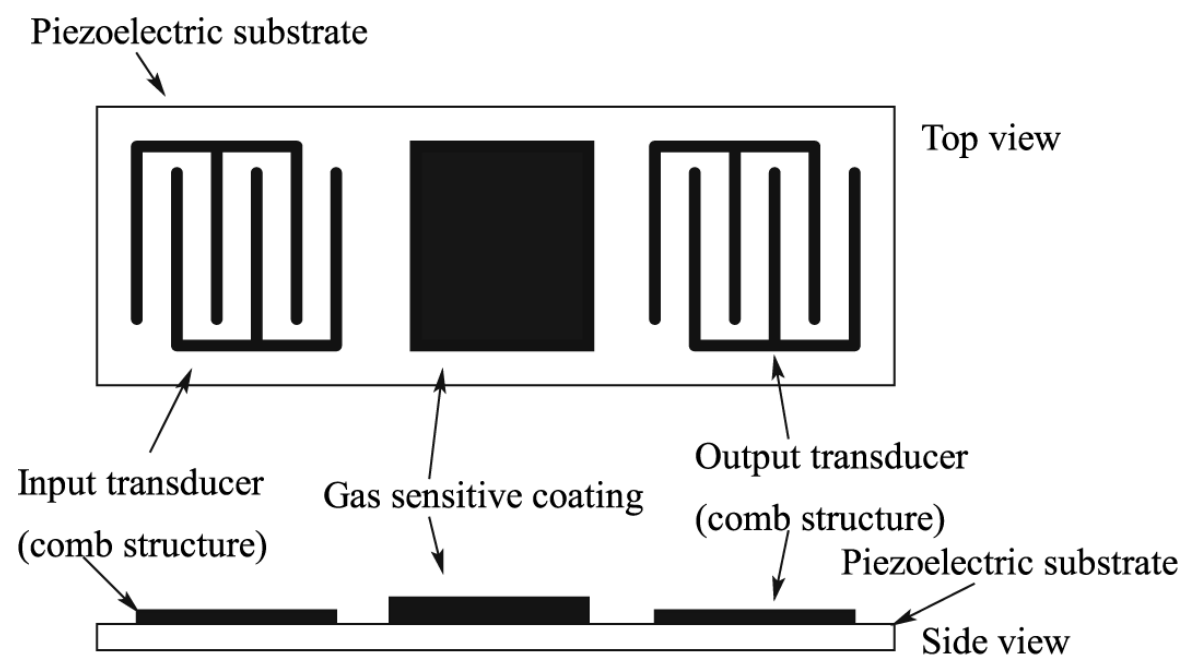

Figure 2.1: A representation of surface acoustic wave sensor (SAW) (12) 
The infra-red (IR) absorption technique is based on the principle that the amount of absorption of a particular wavelength of IR light is unique for each gas and hence, the reverse is possible. So, when IR radiation is made incident on the analyte gas, a particular wavelength of that radiation is absorbed corresponding to the type of analyte gas. So, by matching the obtained result to the standard predetermined values, the type of gas can be determined. For instance, methane has an absorption wavelength of nearly $3000 \mathrm{~cm}^{-1}$ and $1300 \mathrm{~cm}^{-1}$ as shown in Figure 2.2. Also, the concentration of the analyte gas can be determined by knowing the amount of absorption.

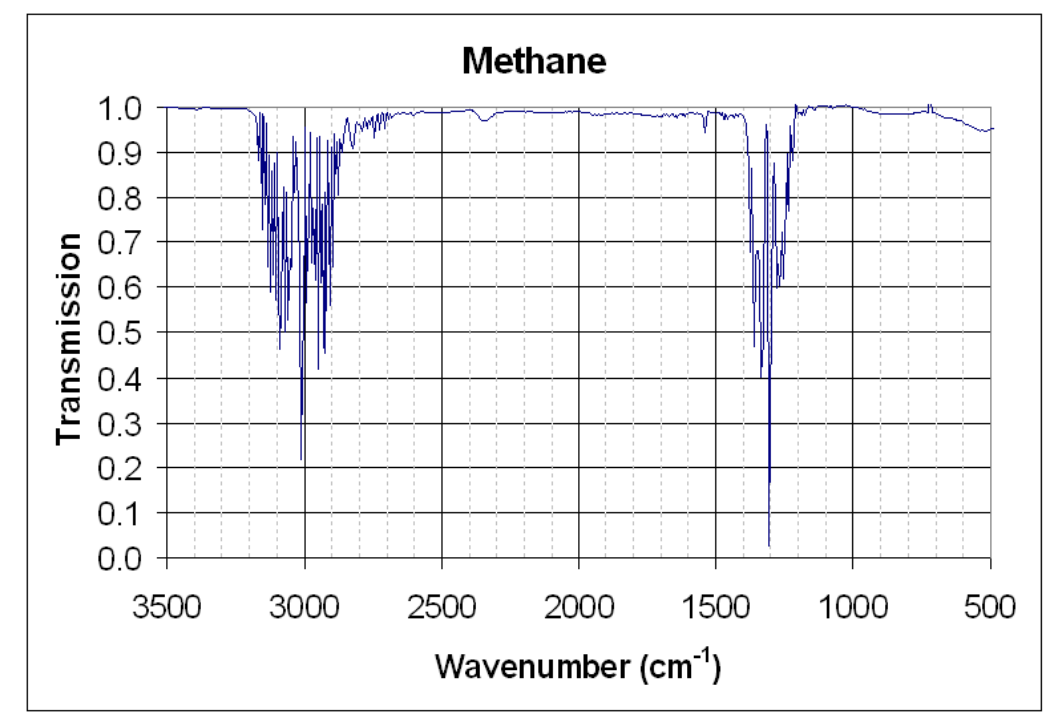

Figure 2.2: Infrared spectrum of methane (13)

The major drawbacks of this type of detection technique are that these sensors can operate only at temperatures $<70{ }^{\circ} \mathrm{C}$ and are expensive.

Gas chromatography type detection system first separates the different components in the mixture and then analyzes each of them using flame ionization detector. This type of detection system is more suitable for volatile organic compounds (VOC's). But for detection of gases like $\mathrm{CO}$, carbon dioxide $\left(\mathrm{CO}_{2}\right)$, sulphur dioxide $\left(\mathrm{SO}_{2}\right)$, nitrogen monoxide $(\mathrm{NO})$, hydrocarbons ( $\left.\mathrm{HC}\right)$ and ammonia $\left(\mathrm{NH}_{3}\right)$ which are relatively inert, the principle of non-dispersive infrared detection (14) is used. Here, depending on the wavelength and amount of absorption, the concentration of the gases can be determined. Chromatographic type of detection system though bulky, can give 
minute details of the presence of any kind of toxic gases present in the mixture (15). But, this is not suitable for high temperature operations (only $<70{ }^{\circ} \mathrm{C}$ ) and is expensive.

In semiconductor type of gas sensors the analyte gas adsorbs on the surface of the sensing material and changes the resistance of the material which acts as the sensing signal. Semiconducting gas sensors are attractive for sensing operations from room temperature to 400 ${ }^{\circ} \mathrm{C}$. But for high temperatures their sensitivity decreases (16). These sensors typically use metal oxides or silicon as the sensing element in their structures. They mainly operate on the principle that when sensing element of the sensor is exposed to the analyte gas, the gas adsorbs on the surface of it, which results in a change in the conductivity of the sensing element. This is used as a sensing signal to detect the presence of harmful gases. Metal oxide (MOX) semiconductor based gas sensors have wide applications in the industries to detect the gas leaks (safety) and for the presence of highly toxic gases like (CO) (17), $\mathrm{NO}_{\mathrm{x}}(18)$ and $\left(\mathrm{NH}_{3}\right)$ (19) etc. They show good response towards the analyte gases but have high cross-sensitivity towards other gases also. Also, they are not capable of operating in the harsh environment like at temperatures $>500{ }^{\circ} \mathrm{C}$. Hence, they find applications mainly in the low-temperature operational conditions. A typical semiconductor gas sensor is shown in Figure 2.3, where there are interdigited electrodes on which sensing material is placed and the change in resistance of this sensing element when exposed to the analyte gas serves as the sensing signal.

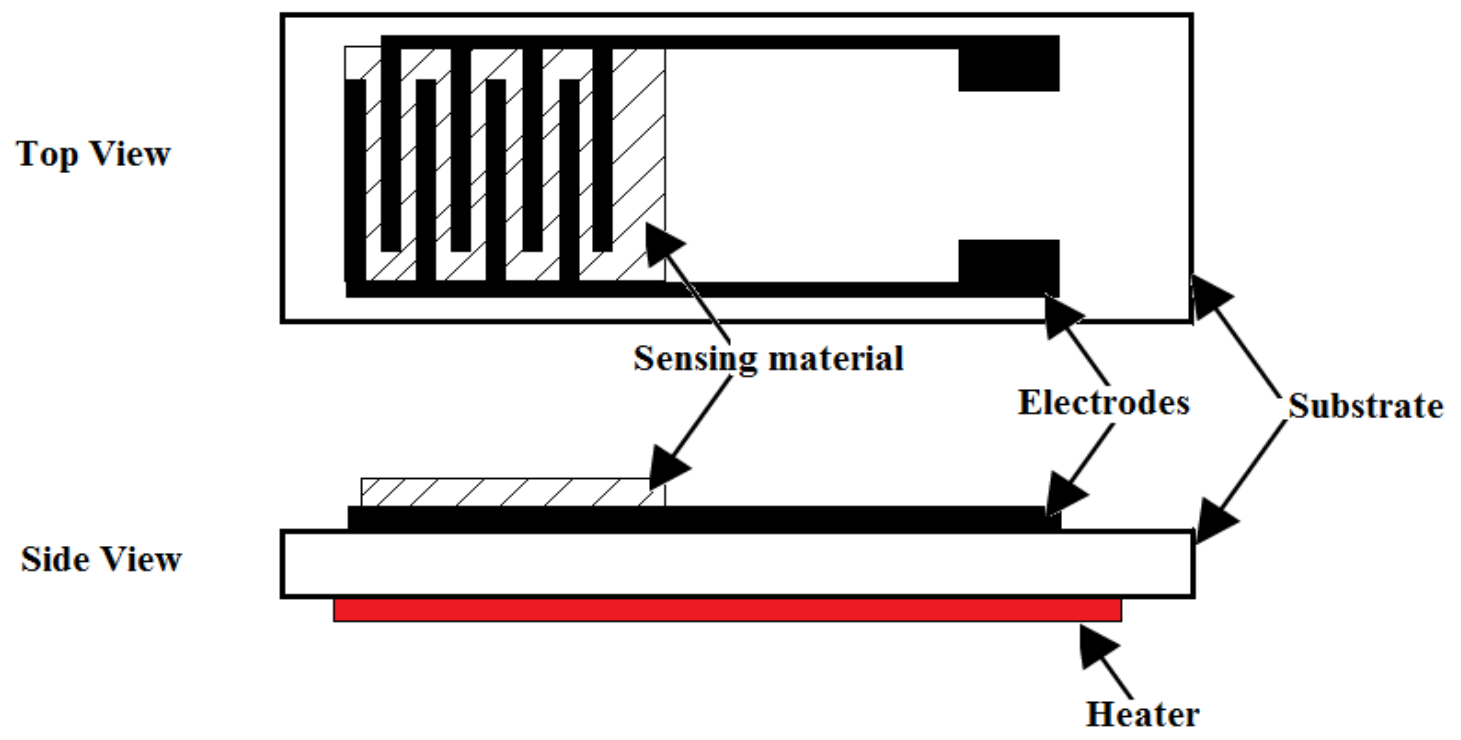

Figure 2.3: Graphical representation of semiconductor gas sensor 
Figure 2.4 shows response of $\mathrm{ZnO}$ nanorods towards $\mathrm{CO}$ detection at $300{ }^{\circ} \mathrm{C}$. When palladium nano particles are suspended over their surface, the response characteristics improved. The principle of operation is that when the sensor is first exposed to oxygen, the oxygen atoms get adsorbed on the $\mathrm{ZnO}$ surface as $\mathrm{O}^{-}$ions. Now, when $\mathrm{CO}$ is introduced these adsorbed oxygen ions combine with $\mathrm{CO}$ to form $\mathrm{CO}_{2}$ and releasing an electron (Equation 2.2). The theory behind this can be explained with the help of the band diagram of $\mathrm{ZnO}$ nanorods when exposed to $\mathrm{CO}$ gas as shown in Figure 2.5. It shows that the $\mathrm{e}^{-}$released during the oxidation of $\mathrm{CO}$ to $\mathrm{CO}_{2}$ increases the $\mathrm{e}^{-}$in the conduction band and thus decreases the depletion region. This hence decreases the resistance of the $\mathrm{ZnO}$ nanorods which can be measured by the configuration as shown in Figure 2.3. Still the stability and response of semiconductor sensors over $500{ }^{\circ} \mathrm{C}$ have to be addressed.

$$
\mathrm{CO}+\mathrm{O}_{\text {ad }}^{-}=\mathrm{CO}_{2}+e^{-} \quad \mathbf{2 . 2}
$$

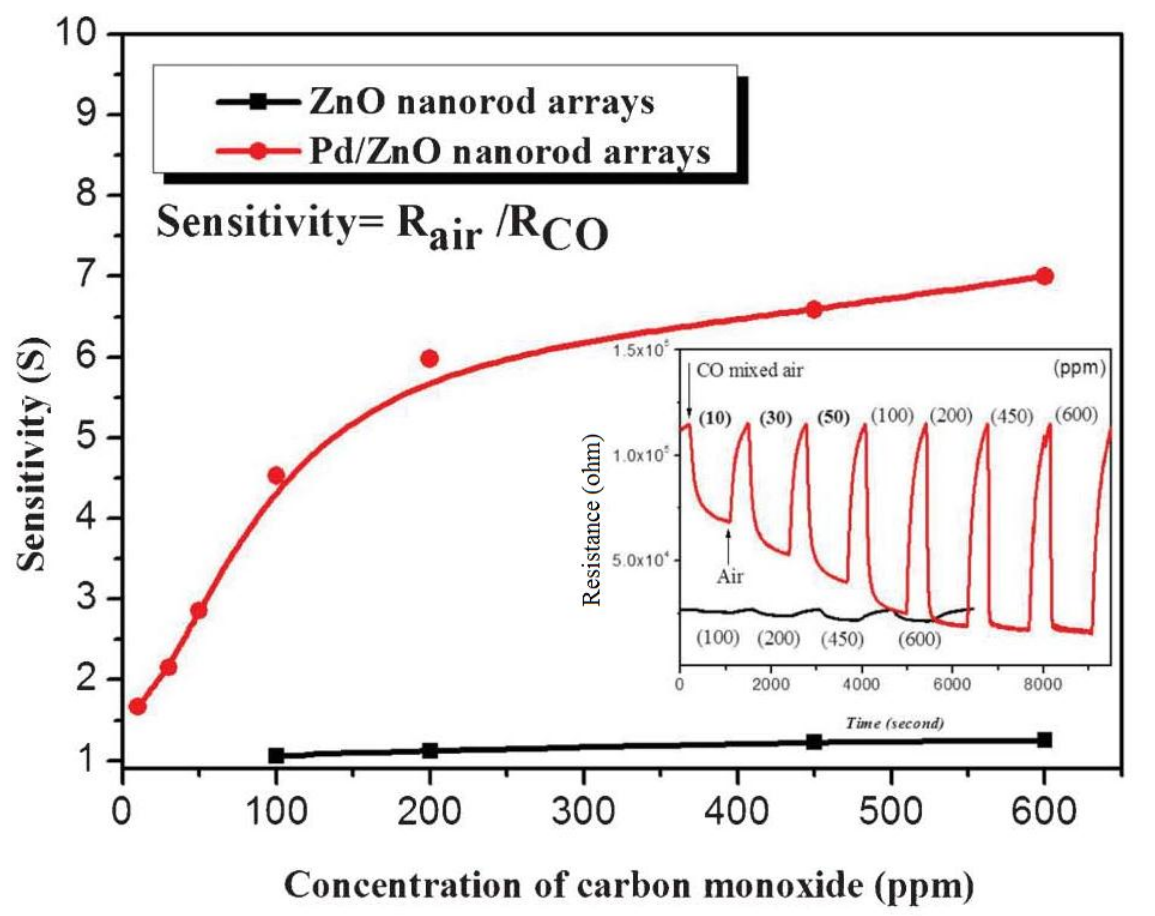

Figure 2.4: Response to $\mathrm{Pd} / \mathrm{ZnO}$ nanorod arrays to $\mathrm{CO}$ concentration (20) 




Figure 2.5: Band diagrams of $\mathrm{ZnO}$ nanorods when exposed to $\mathrm{CO}$ (20)

Hence, there is a need for an efficient system for sensing the exhaust gases. Currently, emissions in the urban areas are being monitored by analytical methods like gas chromatography etc. which are very costly, and which require expertise to operate them. Due to this reason, in a town, less number of sites are chosen for monitoring the harmful emissions. If a reliable and cost effective system that is capable of detecting the emissions is developed, then more sites can be monitored for the presence of toxic gases, leading to a cleaner and safer environment. Also, as the time goes by, more stringent norms will be laid on the emissions (mainly $\mathrm{NO}_{\mathrm{x}}, \mathrm{HC}$ 's and $\mathrm{CO}$ ) from automobiles. To meet these norms and for controlling the emissions, on-board diagnostics should be employed which would directly help in controlling the combustion process to give lesser emissions and thus leading to a more efficient operation. On an average, the exhaust gas temperatures fall in the range of $400-600{ }^{\circ} \mathrm{C}(21)$. So, a gas sensor that is capable of operating at temperatures more than $400{ }^{\circ} \mathrm{C}$ is required.

\subsection{Solid-Electrolyte (or solid-state) electrochemical gas sensors}

The main advantage of electrochemical system is that it directly converts the analyte information into an electric signal like EMF or current which may be directly linked to an electronic circuit for controlling the required system. The solid state electrochemical based devices can further equip a reduction in size to fit direct application in on board diagnostics.

Solid-electrolyte based electrochemical gas sensors is a promising technology and have gained recent interest for their capability to be used in harsh environments $\left(>500{ }^{\circ} \mathrm{C}\right)$. These sensors 
being sensitive to relatively low concentrations of gases (For eg: $<10 \mathrm{ppm} \mathrm{CO}$ at $600{ }^{\circ} \mathrm{C}(22)$ ), having fast response times along with being simple and compact are drawing attention from researchers to further investigate their response characteristics towards different gases. Solid electrolytes that were investigated in sensor research are mostly oxygen ion conducting like YSZ and CGO (23). Apart from these, sodium ion conducting electrolytes like beta alumina or NASICON (24), (25), (26) have also been investigated. NASICON electrolytes do not find much applications for high temperature applications $\left(>500{ }^{\circ} \mathrm{C}\right)$ and have less stability towards gases like $\mathrm{SO}_{2}$ (27). But, oxygen ion conducting electrolytes overcome these disadvantages and prove to be promising.

In the present thesis yttrium stabilized zirconium (YSZ) is used as the solid electrolyte material due to its high temperature withstanding capability and increased ionic transport property at elevated temperatures (28), (29), (30), (31), (32), (33), (34). The ionic conduction mechanism in zirconia was first investigated and interpreted by Carl Wagner in 1943 (35). Measuring chemical potentials by using solid-electrolytes was first demonstrated by kiukkola et al. in the year 1957 (36). Also, it has been successfully applied in the automobile sector as an oxygen sensor for the past 3 decades. That is why even today zirconia based sensor for the oxygen detection (lambda sensors) is still employed in automobiles which provide vital information for electronic fuel injection system.

Addition of yttrium oxide (in which the oxidation state if yttrium is $+3, \mathrm{Y}^{+3}$ ) to zirconium oxide (in which the oxidation state of Zirconia is $+4, \mathrm{Zr}^{+4}$ ), creates oxygen vacancies throughout the zirconia matrix to facilitate electron neutrality and hence making the solid structure to be highly conductive to oxygen ions. Due to this the YSZ solid substrate allows the oxygen diffusion through the solid structure via vacancies present in it.

In the past decade, much progress has been made in the research and development of solid-state electrochemical gas sensors for practical applications. Investigations on different electrode materials and fabrication processes for better sensing of the gases like $\mathrm{NO}_{\mathrm{x}}, \mathrm{HC}^{\prime}$ 's and $\mathrm{CO}$ were carried out extensively. Solid-state electrochemical gas sensors can be applied in situ monitoring as they can reduce the time lag between sensor signal and analyzation greatly, and gives scope to efficient systems. 
The electrochemical gas sensors are classified according to the following operation process:

- Potentiometric

- Amperometric

- Impedancemetric

In the present thesis emphasis is given on potentiometric type of sensing.

\subsubsection{Potentiometric}

Solid-state potentiometric gas sensors operate on a principle that when the sensor is exposed to the analyte gas, the output signal from the sensor is in the form of EMF which is the potential difference between the working electrode and the reference electrode. A typical potentiometric gas sensor with sensing and reference electrodes is shown in Figure 2.3. This is called a tubular configuration. In this type of design, the sensor consists of an YSZ electrolyte that has two electrodes, one on the outer surface (sensing electrode) which is exposed towards the analyte gas and the other on the inner surface (reference electrode) which is exposed to ambient air. When the analyte gas flows over the sensing electrode of the sensor, an electromotive force is developed across the two electrodes which can be measured.

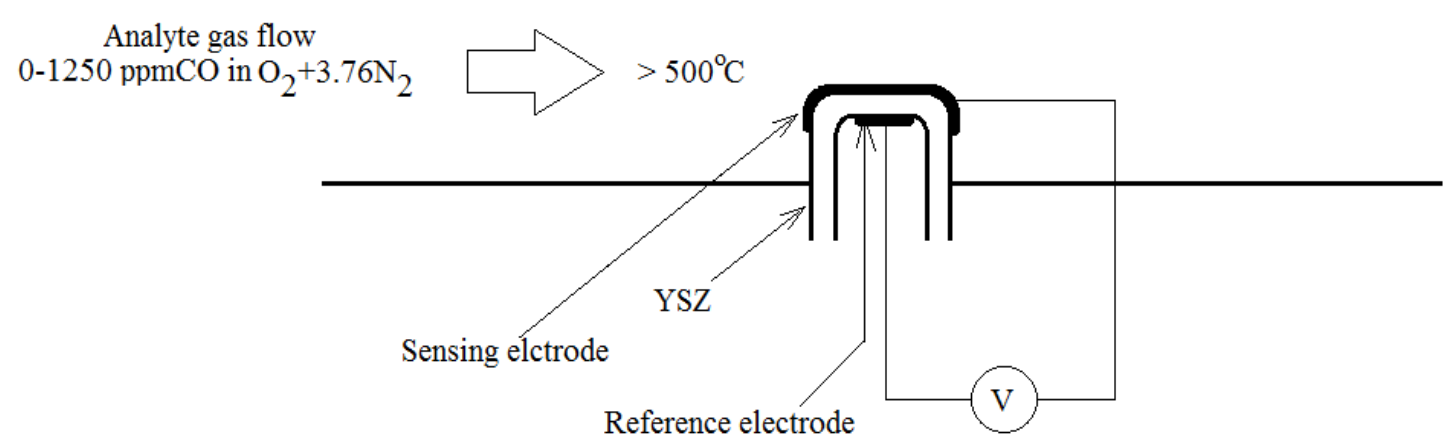

Figure 2.6: Typical structure of a tubular potentiometric device for testing gases

This has applications in automobiles as a sensor to detect the percentage of oxygen in the exhaust stream (a lambda sensor or a lambda probe). The lambda sensor measures the EMF for a difference in partial pressures of oxygen in the exhaust and the ambient. The EMF $(E)$ generated for a potentiometric cell $\mathrm{O}_{2}\left(P_{O_{2}}^{I}\right), \mathrm{Pt} / \mathrm{YSZ} / \mathrm{Pt}, \mathrm{O}_{2}\left(P_{O_{2}}^{I I}\right)$ can be measured by the Nernst equation given by 


$$
E=\frac{R T}{4 F} \ln \frac{P_{O_{2}}^{I I}}{P_{O_{2}}^{I}}
$$

Here, $\mathrm{R}$ is the gas constant, $\mathrm{T}$ is the temperature, $\mathrm{F}$ is the Faraday constant and $P_{O_{2}}^{I} \& P_{O_{2}}^{I I}$ are the respective partial pressures of oxygen in the separated chambers. Here, if $P_{\mathrm{O}_{2}}^{I}$ is known (typically the ambient pressure) then $P_{O_{2}}^{I I}$ can be calculated by measuring the output EMF. So, the principle here lies in measuring the partial pressure of oxygen in the analyte gas, through which the concentration of the $\mathrm{O}_{2}$ present in the exhaust can be interpreted. Responses of potentiometric sensors in which the sensing and reference electrodes are separated can be measured by two configurations. One is a tubular configuration as shown in Figure $\mathbf{2 . 6}$ or by an air tight seal as shown in Figure 2.7. In both the cases, the sensing electrode is exposed to the analyte gas and the reference electrode is exposed to the ambient air.

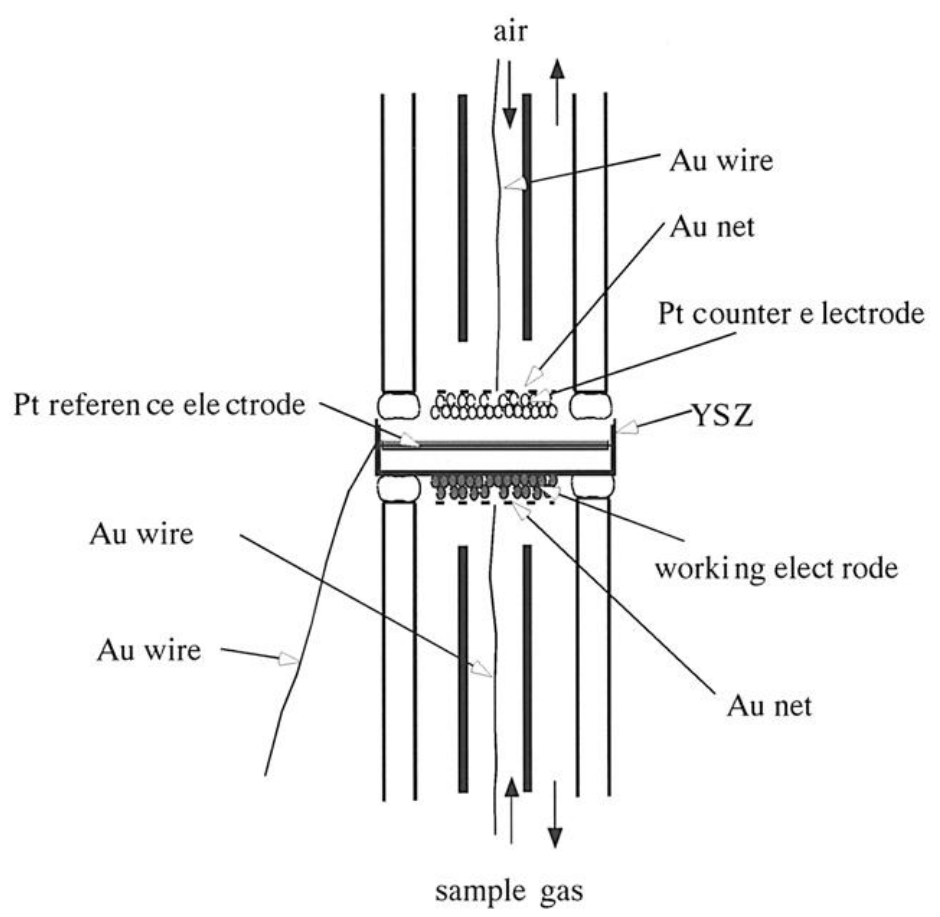

Figure 2.7: Potentiometric sensor with air tight seal (37).

In potentiometric sensors there is another configuration which is addressed by the researchers as a planar configuration in which both the electrodes are exposed to the same analyte gas. This configuration was developed and investigated as this type of design doesn't require gas-tight 
separation between electrodes, making its fabrication and installation easier. Figure 2.8 shows a planar configuration of potentiometric sensors.

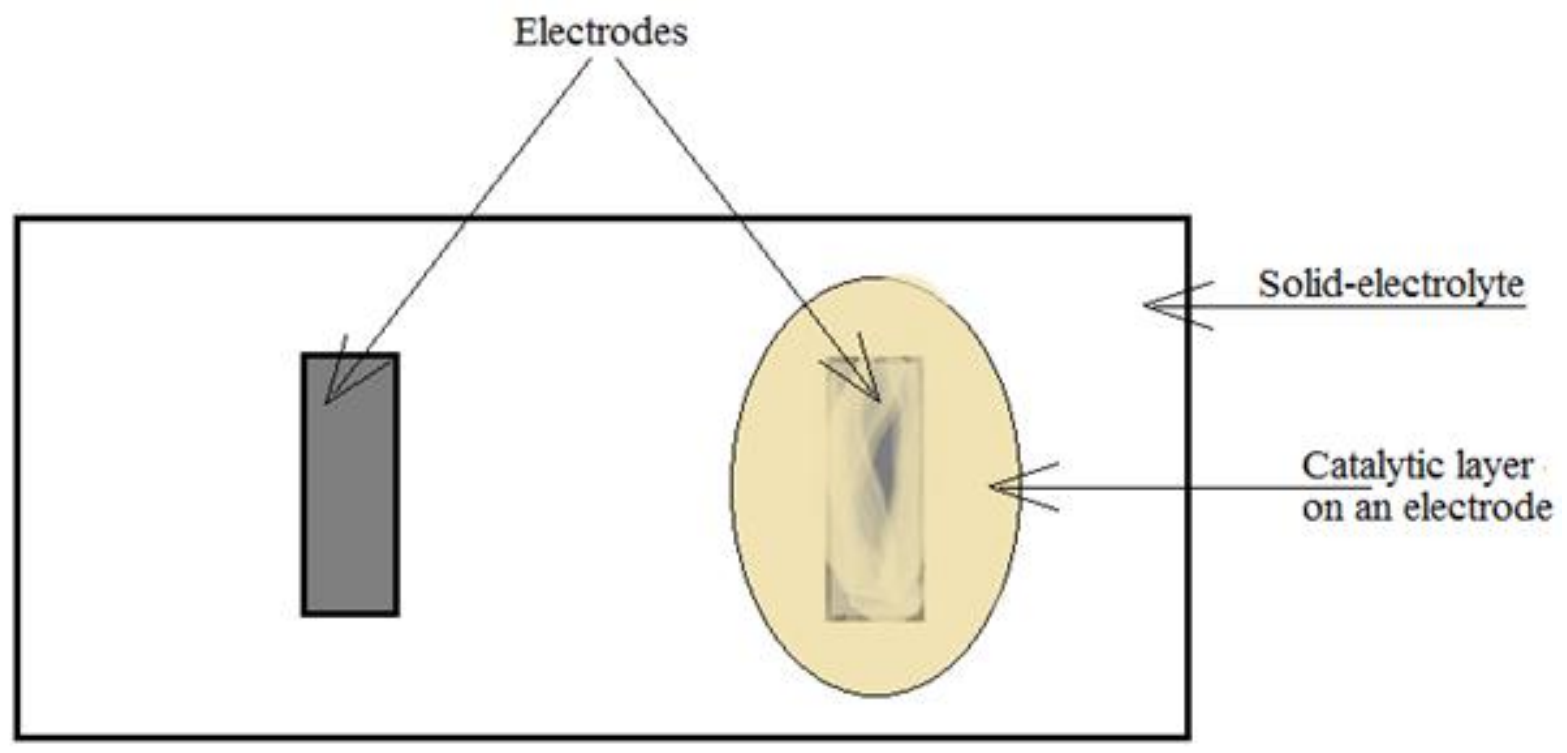

Figure 2.8: A planar configuration of potentiometric sensors.

When a sensor with any of the three configurations given above is placed in the exhaust atmosphere which contains a number of exhaust gases, more than one reducing or oxidizing reactions take place leading to generation of a mixed potential. Many researchers have investigated their response characteristics to different gases like $\mathrm{CO}, \mathrm{HC}$ 's, $\mathrm{NOx}, \mathrm{NH}_{3}$ and volatile organic compounds like toluene etc. The mixed potential theory was observed for the relationship between concentration of the analyte gas and the EMF generated.

\section{Mixed potential sensing theory}

A typical mixed-potential gas sensor is shown in Figure 2.9. There is one electrode on either side of the YSZ electrolyte. This electrode1 / Electrolyte / electrode2 cell is exposed to the same analyte gas mixture. When the sensor is exposed only to air, each electrode-half cell develops a unique potential and the difference in these potentials gives the mixed potential developed by the cell. In the presence of $\mathrm{CO}$, the reactions (2.4) and (2.5) occur at each electrode/electrolyte interface. Due to different rates of electro kinetic reduction and oxidation reactions taking place at each of the electrode/electrolyte interface, different potentials (in $\mathrm{mV}$ ) are generated on each 
electrode. For a particular concentration of $\mathrm{CO}$, a distinctive voltage is generated on each electrode and the difference in the voltages between these electrodes, gives the mixed potential generated by the cell (in $\mathrm{mV}$ ) for that particular concentration of $\mathrm{CO}$ input.

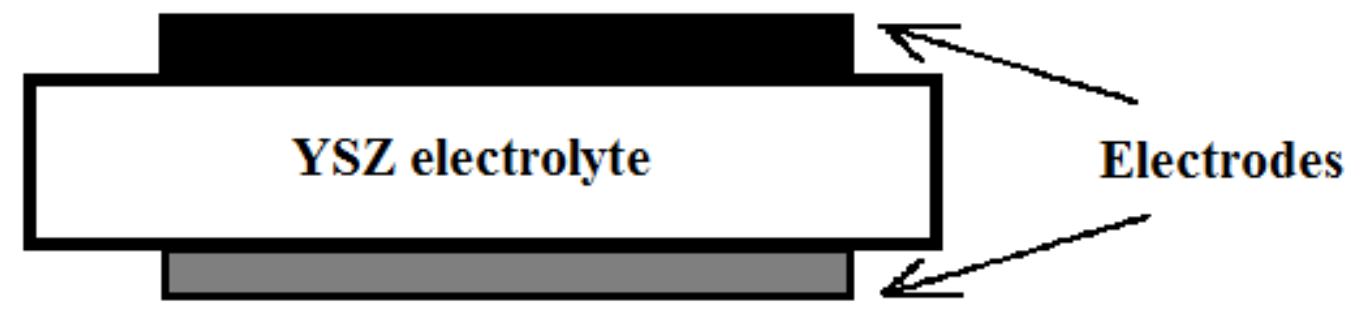

Figure 2.9: Typical mixed potential sensor.

The following reactions take place simultaneously at the electrode/electrolyte interface and thus generate an electrode potential at each of the dissimilar electrodes.

Reduction:

$\mathrm{O}_{2}+4 \mathrm{e}^{-} \rightarrow 2 \mathrm{O}^{2-}$

Oxidation:

$\mathrm{CO}+\mathrm{O}^{2-} \rightarrow \mathrm{CO}_{2}+4 \mathrm{e}^{-}$

So, mixed potential is established at an electrode when the reduction (2.4) and oxidation reactions (2.5), simultaneously take place at the electrodes. In some cases it may be on the electrode surface which is due to heterogeneous reactions and in other cases it is due to the reaction kinetics at electrode/electrolyte interface. As the reaction kinetics depends on the electrode materials, the dissimilar electrodes generate dissimilar electrode potentials. This creates a potential difference across the two electrodes when exposed to $\mathrm{CO}$ gas, which serves as an output signal for the presence of $\mathrm{CO}$ in the gas mixture.

The Figure 2.10 gives a graphic description of the reduction and oxidation reactions happening along with the $\mathrm{O}^{2-}$ ion transport in the electrolyte. 


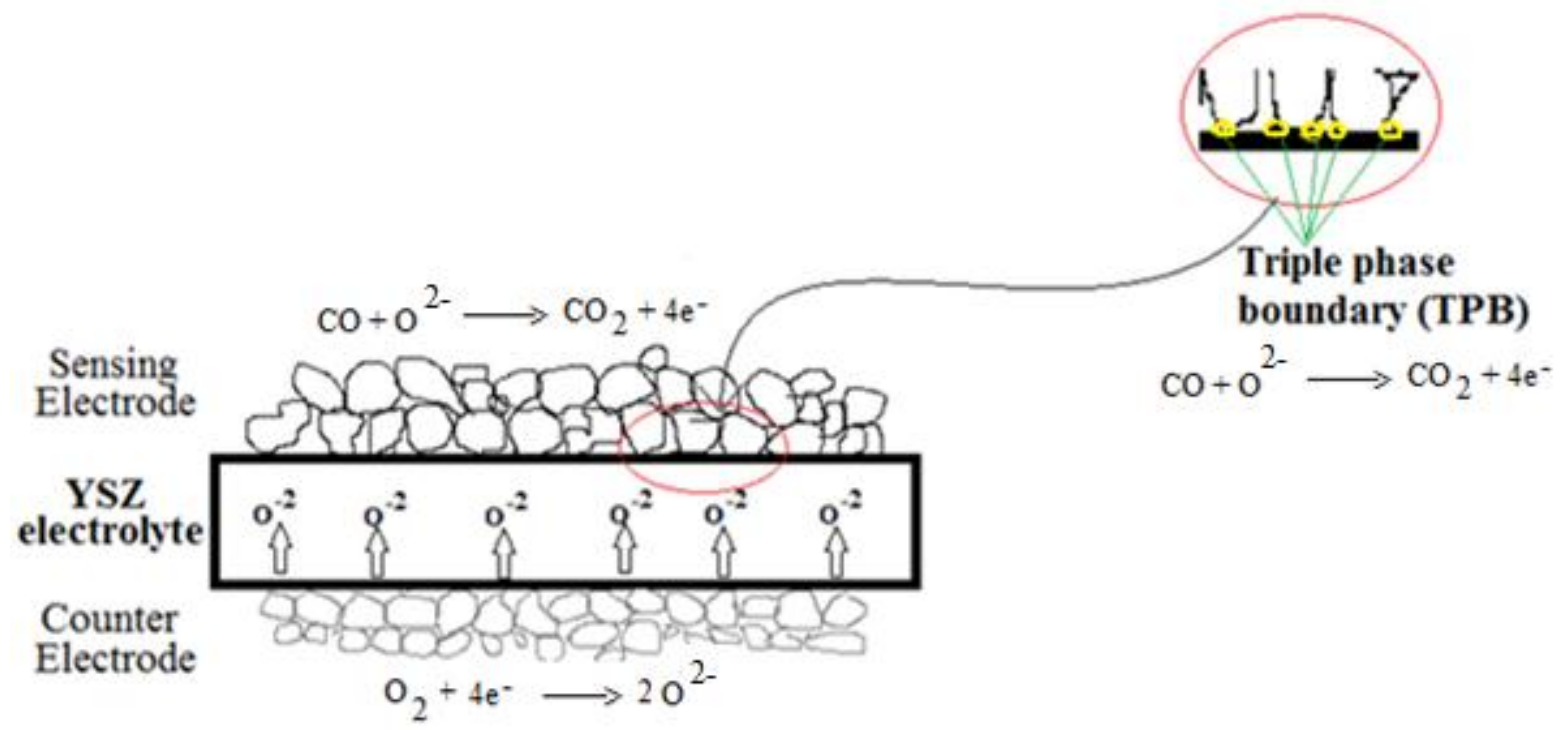

Figure: 2.10: Graphic description of ion transport and triple phase boundary (TPB)

When a planar sensor is exposed to the analyte gas, both the sensing and reference electrodes are exposed to the same gaseous atmosphere. For simplicity assuming that there are only $\mathrm{CO}, \mathrm{O}_{2}$ and $\mathrm{N}_{2}$ in the gaseous stream, $\mathrm{N}_{2}$ being stable doesn't easily participate in the reaction kinetics, but $\mathrm{CO}$ gets oxidized to $\mathrm{CO}_{2}$ at both the electrodes. The oxidation of $\mathrm{CO}$ to $\mathrm{CO}_{2}$ happens through oxidation and reduction reactions given by equations 2.4 and 2.5, and this happens at both the sensing and reference electrodes. As, mentioned previously, the reactions kinetics of oxidation or reduction depend on the electrode material, the electrode/electrolyte interface, porosity. The points of contact of electrode/electrolyte interface are called triple phase boundaries (TPB's) which are active site for electrochemically oxidizing $\mathrm{CO}$ to $\mathrm{CO}_{2}$. The more the active sites, the more is the sensor response output and hence better is the performance. For different electrode materials the mixed electrode potential developed by the cell is different and more the difference in this mixed electrode potential gives a better response called mixed potential response towards a gas. Figure 2.11 shows a polarization curve for a planar sensor having Pt as reference electrode that generate different mixed electrode potentials for CO gas (34). 


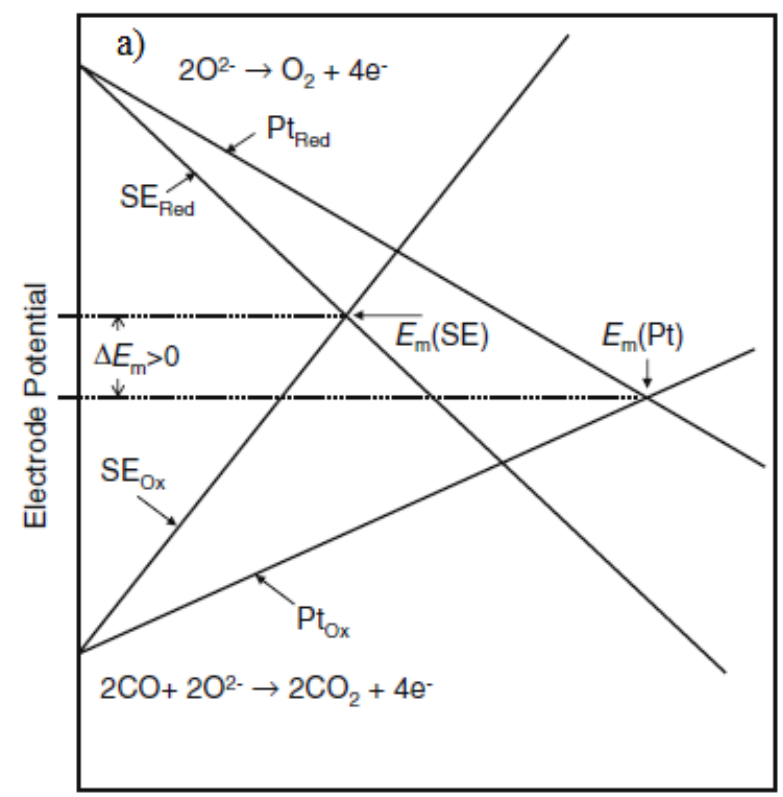

Log Current

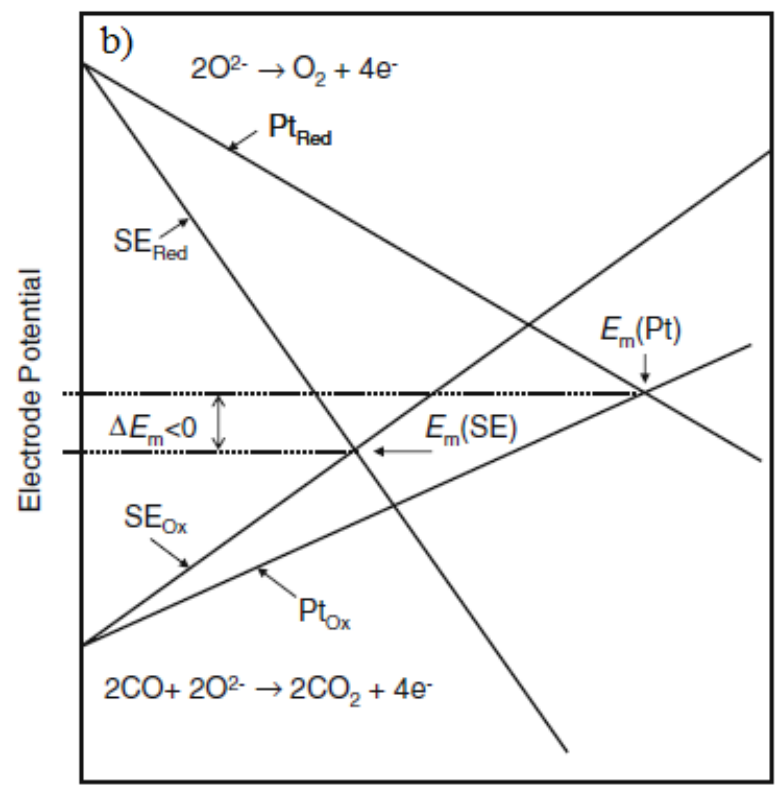

Log Current

Figure 2.11: Polarization curve for $\mathrm{CO}$ oxidation and $\mathrm{O}_{2}$ reduction on dissimilar electrodes a) $\left.\mathrm{E}_{\text {mix }}>0 ; \mathrm{b}\right) \mathrm{E}_{\text {mix }}<0(\mathbf{3 4})$

If on one electrode oxidation (equation 2.5) favors more than reduction (equation 2.4), then the mixed electrode potential developed by the cell would be greater than zero $\left(\mathrm{E}_{\text {mix }}>0\right.$ as shown in Figure 2.11 (a)). But if reverse happens, i.e., the reaction kinetics of equation 2.4 (reduction) is more pronounced than equation 2.5 (oxidation) on the sensing electrode, then the mixed electrode potential developed by the cell would be less than zero $\left(\mathrm{E}_{\text {mix }}<0\right.$ as shown in Figure 2.11 (b)). It must be noted that in both Figure 2.11 (a) and (b), the redox reaction kinetics on Pt electrode is represented the same. This is to emphasize that, depending on the sensing electrode material and its tendency to favor either oxidation or reduction more than the other, the sensor cell would give either a positive or negative response. So, for better response, the sensing materials must be chosen in such a way that $\mathrm{E}_{\mathrm{mix}}$ is more for a particular $\mathrm{CO}$ concentration.

Practical investigation also lead to some electrode configurations that had negative mixed potential response and some others with positive mixed potential response on exposure to $\mathrm{CO}$ gas. Tungsten Oxide $\left(\mathrm{WO}_{3}\right)$ as $\mathrm{SE}$ gave negative EMF response when exposed to $\mathrm{CO}$ whereas $\mathrm{LaFeO}_{3}$ gave positive EMF response to the same $\mathrm{CO}$ concentrations (38). To understand the 
theory behind such mixed potential response and the factors affecting it, Miura et al (39) and Garzon et al (40) gave detailed explanation as follows.

Considering that both the anodic and cathodic reactions occur on the same electrode, the ButlerVolmer equation describes how the electric current on the electrode depends on the electrode potential. A model was developed by N. Miura et.al (39) to find the relation between the EMF generated and the concentration of $\mathrm{CO}$ present.

The following equations are Butler-Volmer reactions for the electric current densities generated due to the reducing and oxidizing reactions.

$i_{O_{2}}=i_{O_{2}}^{o} \exp \left\{-4 \alpha_{1} F\left(E-E_{O_{2}}^{o}\right) / R T\right\}$

$i_{C O}=i_{C O}^{o} \exp \left\{2 \alpha_{2} F\left(E-E_{C O}^{o}\right) / R T\right\}$

Here,

$i_{O_{2}}$ and $i_{C O}$ are the respective electric currents densities developed for the equations 2.4 and 2.5 respectively, $i^{o}$ is the exchange current density, $\alpha$ is the charge transfer coefficient, $E$ is the electrode potential, $E^{o}$ is the equilibrium electrode potential $\mathrm{R}$ is the molar gas constant, $\mathrm{T}$ is the temperature and $\mathrm{F}$ is the Faraday constant.

If an electrode in the mixed-potential cell favors Equation 2.4, then more non-Nernstian response can be observed. Generally, the electrodes are chosen in such a way that Equation 2.5 dominates sufficiently large on one electrode than the other electrode to see a positive EMF in the sensor output. In this way, intense non-Nernstian response in $\mathrm{mV}$ can be observed. For a steady response to a particular $\mathrm{CO}$ concentration, the $\mathrm{O}^{2-}$ ions formed on the counter electrode must be transported to the sensing electrode through the electrolyte and combine with $\mathrm{CO}$ at the triple phase boundaries and resulting in the release of $\mathrm{e}^{-}$. That means the electrons taken on the counter electrode side is equal to the electrons released on the sensing electrode side, due to which potential difference is being created between the electrodes. Hence, the electric current densities of the electrodes must be the same for steady response to a particular concentration of $\mathrm{CO}$. 
According to the assumption (39),

$i_{O_{2}}^{o}=-B_{1} C_{O_{2}}^{m}$

$i_{C O}^{o}=B_{2} C_{C O}^{n}$

Here, $\mathrm{C}$ stands for the concentration of $\mathrm{O}_{2}$ or $\mathrm{CO}$ and $\mathrm{B}_{1}, \mathrm{~B}_{2}, \mathrm{~m}, \mathrm{n}$ are constants. Here, $i_{\mathrm{O}_{2}}$ and $i_{C O}$ are opposite in sign but their modulus is equal for some mixed potential to be developed to a particular concentration of $\mathrm{CO}$.

$\Rightarrow\left|i_{O_{2}}\right|=\left|i_{C O}\right|$

Hence, by substitution of the assumed exchange current density values in equations $\mathbf{2 . 6}$ and 2.7 and further employing equation 2.10, E can be written as

$$
E=\frac{2 \alpha_{1} E_{O_{2}}^{o}+\alpha_{2} E_{C O}^{o}}{\alpha_{2}+2 \alpha_{1}}+\frac{R T}{2 F\left(\alpha_{2}+2 \alpha_{1}\right)} \ln \left[\frac{B_{1} C_{O_{2}}^{m}}{B_{2} C_{C O}^{n}}\right]
$$

Assuming,

$$
\begin{aligned}
& E_{o}=\frac{2 \alpha_{1} E_{O_{2}}^{o}+\alpha_{2} E_{C O}^{o}}{\alpha_{2}+2 \alpha_{1}}+\frac{R T}{2 F\left(\alpha_{2}+2 \alpha_{1}\right)} \ln \left[\frac{B_{1}}{B_{2}}\right] \text { and } \\
& A=\frac{R T}{2 F\left(\alpha_{2}+2 \alpha_{1}\right)} \\
& \mathrm{E}_{\text {mix }} \text {, could be written as }
\end{aligned}
$$

$E_{m i x}=E_{o}+A m \ln C_{O_{2}}-A n \ln C_{C O}$

Again assuming that the Oxygen concentration $C_{O_{2}}$ in the test gas is kept constant, then equation 2.11 simplifies to

$$
E_{\text {mix }}=E_{o}{ }^{\prime}-n A \ln C_{C O}
$$


Here, $E_{o}^{\prime}$ and $A$ are constants. So, the mixed potential generated in the sensor is directly proportional to the natural ln $\mathrm{CO}$ concentration. This logarithmic correlation was observed by Niura et al (39) for sensing CO using stabilized zirconia and couple of oxide electrodes.

According to Garzon et al (40), for very low concentrations of $\mathrm{CO}$ with respect to oxygen, the oxidation reaction of $\mathrm{CO}$ might be mass transport limited in which the current generated in that case can be expressed by the following

$$
i_{C O}=2 F A D_{C O} \frac{C_{C O}}{\delta},
$$

Where, $A$ is the electrode area, $D_{C O}$ is the diffusion coefficient of $\mathrm{CO}$ and $\delta$ is the diffusion boundary layer thickness. Again $F$ is the Faraday constant and $C_{C O}$ is the concentration of CO.

Now, if the oxygen reduction kinetics follow Taefel type behavior (Equations 2.6 and 2.8) and the $\mathrm{CO}$ oxidation kinetics are mass transport limited then, the mixed potential would be

$$
E_{\text {mix }}=E_{O_{2}}^{o}-\frac{R T}{4 \alpha_{1} f} \ln \frac{2 F A D_{C O} C_{C O}}{B_{1} \delta C_{O_{2}}^{m}}
$$

In this case also, there is logarithmic dependence of $E_{m i x}$ on concentration of $\mathrm{CO}\left(C_{C O}\right)$.

At low overpotential regions, that means when mixed potential occurs near to the equilibrium potential of Oxygen ( $E_{\mathrm{O}_{2}}^{o}$ ), the Butler-Volmer equation for the oxygen reduction kinetics can be expressed by

$i_{O_{2}}=i_{O_{2}}^{o} 4 F\left(E-E_{O_{2}}^{o}\right) / R T$

So, if the CO oxidation kinetics follow Tafel type behavior (Equations 2.7 and 2.9) for the linear oxygen reduction kinetics (Equations $\mathbf{2 . 1 5}$ and 2.8), then the mixed potential developed is obtained by solving the above equations for which, $E_{m i x}$ could be written as,

$$
E_{m i x}=E_{C O}^{o}+\frac{R T}{2 F \alpha_{2}}\left[\ln \left[\frac{B_{1}}{B_{2}}\right]+\ln \frac{4 F}{R T}\left(E_{m i x}-E_{O_{2}}^{o}\right)+m \ln C_{O_{2}}-n \ln C_{C O}\right]
$$

Now, if the behavior of the sensor is such that the $\mathrm{CO}$ oxidation kinetics are mass transport limited for linear Butler-Volmer reduction kinetics, the mixed potential generated would be 
obtained by solving for $E$ using equations $2.15,2.13,2.8$ and 2.9. The mixed potential $E_{m i x}=E$ can be written as,

$E_{m i x}=E_{O_{2}}^{o}-R T \frac{A D_{C O} C_{C O}}{2 B_{1} \delta C_{O_{2}}^{m}}$

Equation 2.17 shows that the mixed potential $\left(E_{m i x}\right)$ developed is linearly proportional to the concentration of $\mathrm{CO}\left(C_{C O}\right)$.

So, for the mixed potential response, the response behavior depends on 4 types

1) The Tafel type for both oxidation and reduction (Eq. 2.12)

2) Mass transport limited for CO oxidation and Tafel type for oxygen reduction (Eq 2.14)

3) Linear Butler-Volmer oxygen reduction and Tafel type CO oxidation (Eq 2.16)

4) Mass transport limited CO oxidation and linear Butler-Volmer oxygen reduction kinetics (Eq 2.17)

Hence, it is necessary to investigate the electrokinetic and heterogeneous catalytic properties of the electrodes in order to find the type of mixed potential response behavior (40).

In planar configuration also the response is linear and log linear to the concentration of the exhaust gases depending on the response behavior of the sensor. For instance, Garzon et al reported linear relationship between $\mathrm{CO}$ concentration and the EMF generated for the cell $\mathrm{Pt} / \mathrm{Ce}_{0.8} \mathrm{Gd}_{0.2} \mathrm{O}_{1.9} / \mathrm{Au}$ (40) shown in Figure 2.12. In a concentration range of 0-500 ppm CO, Garzon et al found a linear relationship between the EMF and concentration of CO which can be explained by equation 2.17 . 


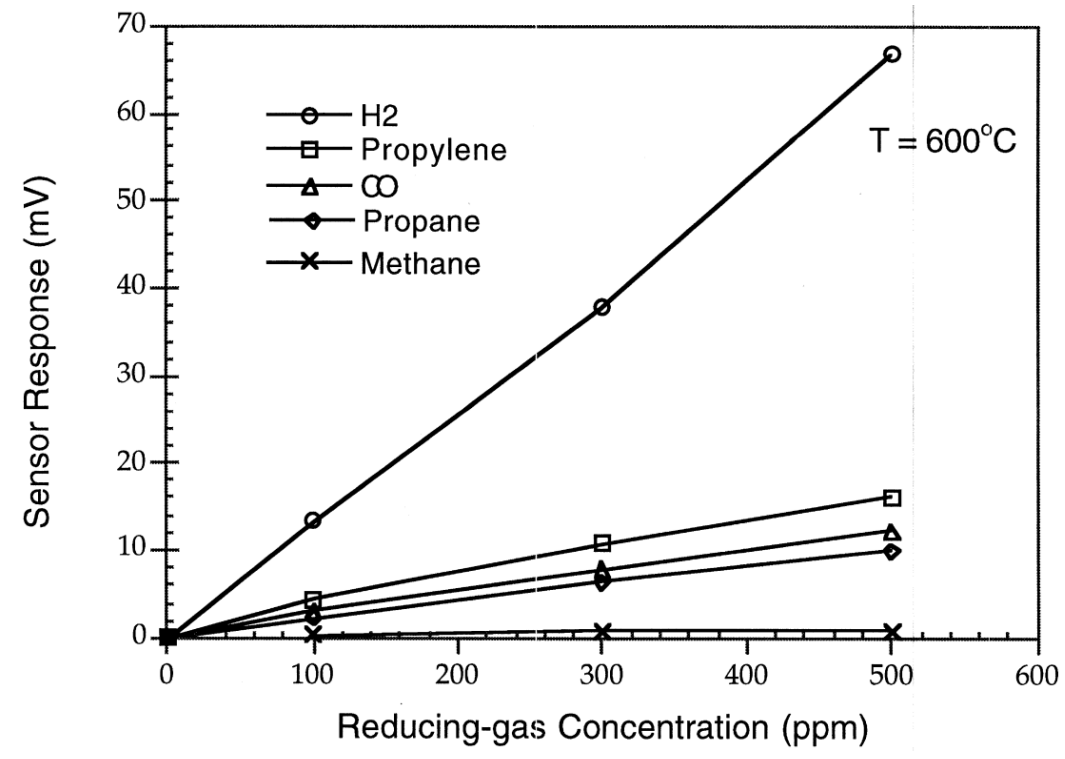

Figure 2.12: Voltage generated by the cell $\mathrm{Pt} / \mathrm{Ce}_{0.8} \mathrm{Gd}_{0.2} \mathrm{O}_{1.9} / \mathrm{Au}$ for different reducing gases (40).

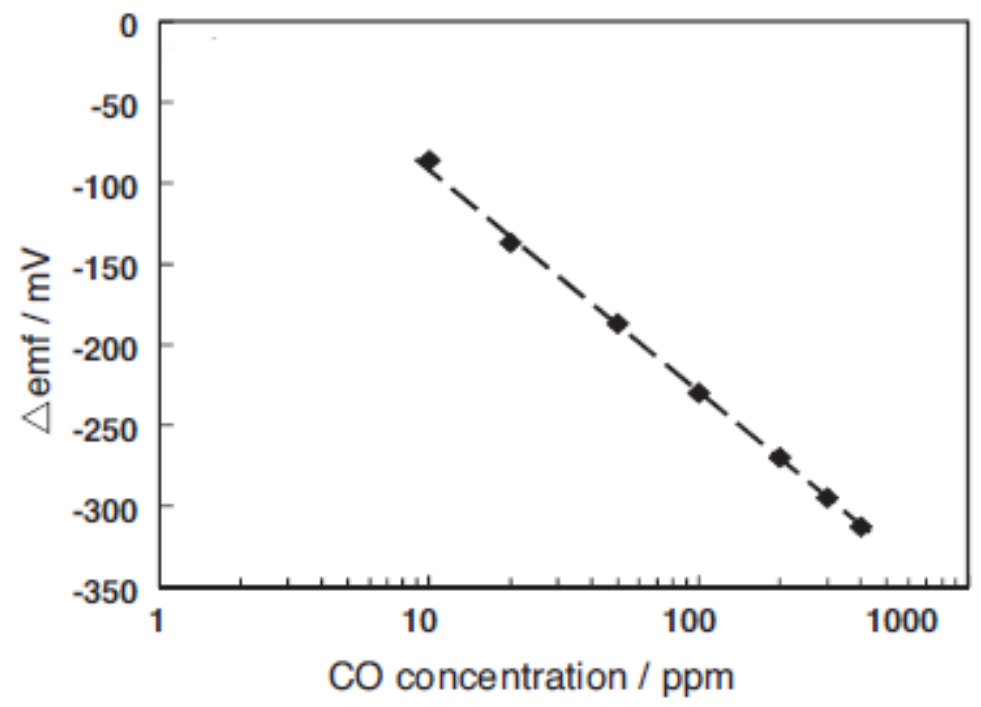

Figure 2.13: Linear variation of EMF to $\ln (\mathrm{CO}$ concentrations) of sensors with cell structure of $\mathrm{Pt} / \mathrm{YSZ} / \mathrm{Nb}_{2} \mathrm{O}_{5}+\mathrm{Au}$ at $450^{\circ} \mathrm{C}(\mathbf{4 1})$.

The EMF response of the planar sensors with cell structure Pt/YSZ/Nb ${ }_{2} \mathrm{O}_{5}$ was reported to be proportional to ln (concentration of $\mathrm{CO}$ gas), which is given by the Nernst equation 2.18. 
$E_{\text {mix }}=E^{o}+\frac{R T}{n F} \ln \frac{C_{O_{2}}}{C_{C O}} \quad \mathbf{2 . 1 8}$

Where, $E^{o}$ is the standard electrode potential, $\mathrm{R}$ is the universal gas constant, $\mathrm{T}$ is the temperature of operation, $\mathrm{n}$ is the number of electrons taking part in the reaction and $C_{\mathrm{O}_{2}}$ and $C_{C O}$ are the respective concentrations of oxygen and carbon monoxide.

There were also few cases in which the air tight configuration Figure 2.7 generated EMF that was linearly dependent on the concentration of the CO gas. For instance, Hibino et al (37) investigated the effect of $\mathrm{MnO}_{2}$ loading in $\mathrm{In}_{2} \mathrm{O}_{3}$ on the sensing characteristics towards different gases and observed that the air tight configuration of a potentiometric based sensor showed a linear relationship between the EMF generated and concentrations of gases as shown in Figure 2.14. This might be due to the mixed potential developed on the SE due to different rates of redox reactions taking place on the electrodes.

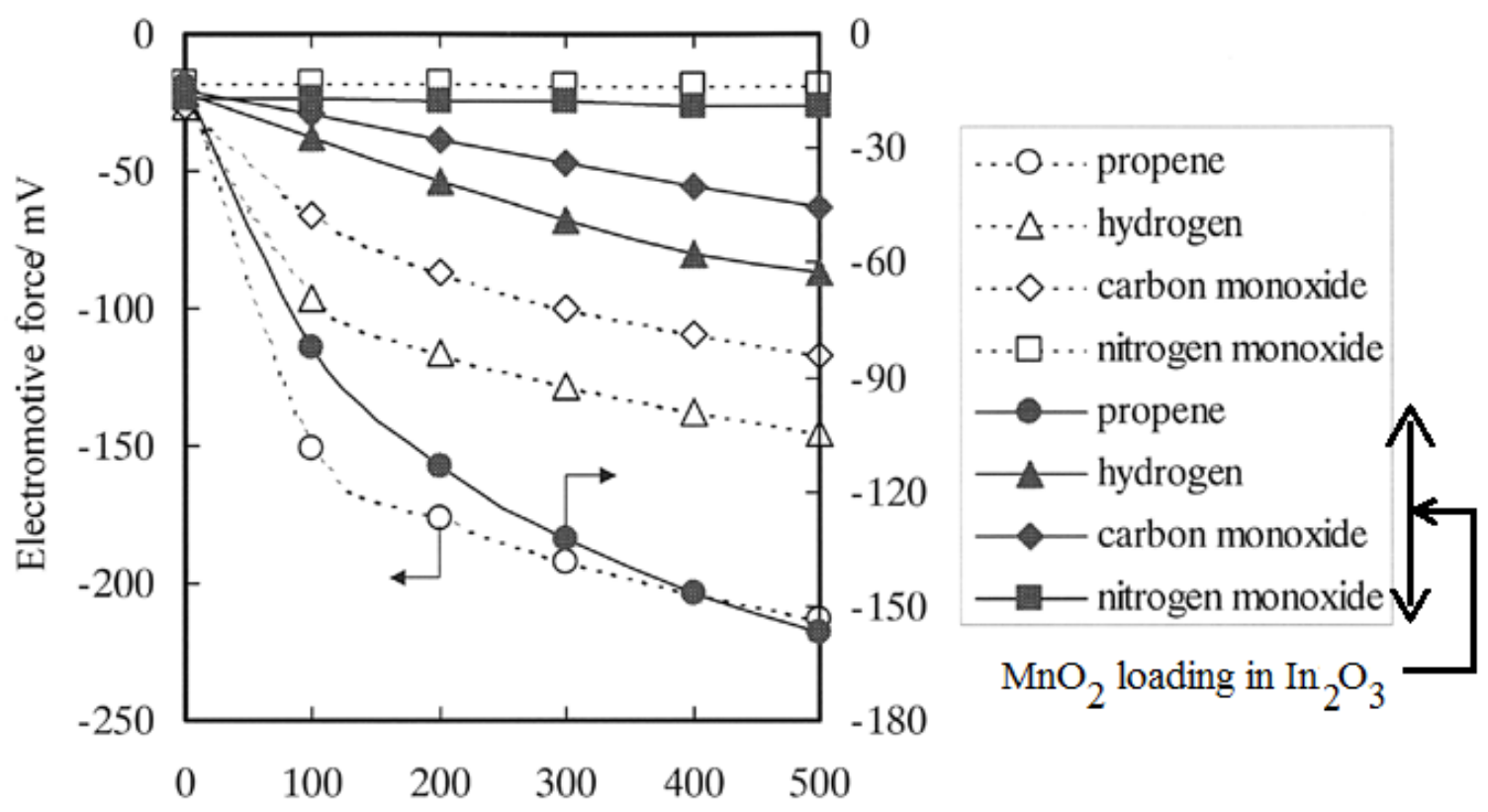

Gas concentration / ppm

Figure 2.14: Dependencies of EMF values of pure and $\mathrm{MnO}_{2}$ containing $\operatorname{In}_{2} \mathrm{O}_{3}$ electrodes on gas concentration (37).

Materials investigated for planar type configuration include oxides like $\mathrm{Nb}_{2} \mathrm{O}_{5}, \mathrm{CuO}, \mathrm{NiO}, \mathrm{WO}_{3}$, $\mathrm{In}_{2} \mathrm{O}_{3}, \mathrm{Al}_{2} \mathrm{O}_{3}, \mathrm{Fe}_{2} \mathrm{O}_{3}, \mathrm{Pr}_{6} \mathrm{O}_{11}$ etc, perovskites, like $\mathrm{LaFeO}_{3}, \mathrm{La}_{0.8} \mathrm{Sr}_{0.2} \mathrm{FeO}_{3}, \mathrm{LaMnO}_{3}, \mathrm{LaCuO}_{4}$ etc 
and pure metals like $\mathrm{Pd}, \mathrm{Pt}, \mathrm{Au}, \mathrm{Ag}$, etc. Of the simple oxides as sensing electrodes like, $\mathrm{WO}_{3}$ showed a selective response when tested in engine exhaust environment but stability and repeatability are still need to be addressed. Perovskites were largely investigated for their response towards various gases like hydrocarbons (propane, ethylene, methane), $\mathrm{NO}_{\mathrm{x}}$ and $\mathrm{CO}$. They withstand high temperatures and also showed repeatability for several times of operation. Apart from this they have good attachment properties with YSZ. Many of those were actually used as cathode materials for SOFC's. But, during long term operation the response is not stable and often the sample to sample reproducibility is difficult. Of this, Miura et al have intensely conducted research on different compounds like oxides, perovskites and pure metals as sensing electrodes for their response to different gases. The following table summarizes the cell structure of different potentiometric sensors and different gases detected, temperature range of operation, and concentration range detected. 
Table 2.1: Brief overview of different potentiometric sensors developed for various gases

\begin{tabular}{|c|c|c|c|c|c|}
\hline $\begin{array}{l}\text { Gases } \\
\text { detected }\end{array}$ & $\begin{array}{l}\text { Cell Structure } \\
\text { gas, electrode RE/YSZ/electrode } \\
\text { SE, gas }\end{array}$ & $\begin{array}{l}\text { Temperatu } \\
\text { re }\left({ }^{\circ} \mathrm{C}\right)\end{array}$ & $\begin{array}{l}\text { Concentration } \\
\text { range }\end{array}$ & Year & Ref. \\
\hline $\mathrm{CO}$ & $\begin{array}{l}\text { air, } \mathrm{Pt} / \mathrm{YSZ} / \mathrm{Pt}, \mathrm{CO}+\text { air } \\
\text { Air+CO, TYP/YSZ/TiO } \\
2, \text { air+CO } \\
\text { Air+CO, } \\
\mathrm{Nb}_{2} \mathrm{O}_{5}(+\mathrm{Au}) / \mathrm{YSZ} / \mathrm{NiO}(+\mathrm{Au}), \\
\mathrm{CO}+\text { air } \\
\text { air, } \mathrm{Pt} / \mathrm{YSZ} / \mathrm{ZCnCr}_{2} \mathrm{O}_{4}+\mathrm{Au}, \\
\text { air+CO }\end{array}$ & $\begin{array}{l}600 \\
500-700 \\
450 \\
550\end{array}$ & $\begin{array}{l}20-4000 \mathrm{ppm} \\
10-1000 \mathrm{ppm} \\
10-400 \mathrm{ppm} \\
20-800 \mathrm{ppm}\end{array}$ & $\begin{array}{r}1998 \\
2010 \\
2011 \\
\\
2012\end{array}$ & $\begin{array}{l}(39) \\
(22) \\
(41) \\
(42)\end{array}$ \\
\hline NOx & $\begin{array}{l}\mathrm{Air}+\mathrm{NO}_{2}, \mathrm{Pt} / \mathrm{YSZ} / \mathrm{NiO}, \text { air }+\mathrm{NO}_{2} \\
\text { Air+ }+\mathrm{NO}_{2}, \mathrm{Pt} / \mathrm{YSZ} / \mathrm{La}_{2} \mathrm{CuO}_{4}, \\
\text { air }+\mathrm{NO}_{2} \\
\text { Air+NO} \\
\text { air }+\mathrm{NO}_{2}, \mathrm{Pt} / \mathrm{YSZ} / \mathrm{Ni}_{0.9} \mathrm{Co}_{0.1} \mathrm{O},\end{array}$ & $\begin{array}{l}850 \\
550-650 \\
800\end{array}$ & $\begin{array}{l}20-500 \mathrm{ppm} \\
20-800 \mathrm{ppm} \\
10-400 \mathrm{ppm}\end{array}$ & $\begin{array}{l}2011 \\
2011 \\
2009\end{array}$ & $\begin{array}{l}\text { (43) } \\
\text { (44) } \\
\text { (45) }\end{array}$ \\
\hline $\begin{array}{l}\mathrm{HC} ' \mathrm{~s} \\
\mathrm{C}_{3} \mathrm{H}_{6}\end{array}$ & $\begin{array}{l}\text { Air, } \mathrm{Pt} / \mathrm{YSZ} / \mathrm{ZCnCr}_{2} \mathrm{O}_{4}+\mathrm{YSZ} \\
\text { air }+\mathrm{C}_{3} \mathrm{H}_{6}\end{array}$ & 550 & 20-800 ppm & 2011 & (46) \\
\hline $\begin{array}{l}\text { VOC's } \\
\text { Toluene } \\
\text { Xylene } \\
\text { Formaldehyde }\end{array}$ & air, $\mathrm{Pt} / \mathrm{YSZ} / \mathrm{NiO}, \mathrm{VOC}$ 's+air & 450 & $\begin{array}{l}10-300 \mathrm{ppb} \\
10-300 \mathrm{ppb} \\
10-300 \mathrm{ppb}\end{array}$ & 2011 & (47) \\
\hline
\end{tabular}




\subsubsection{Amperometric}

In amperometric type of sensing, a voltage is applied across the electrolyte and the resulting current from it serves as a sensing signal. Amperometric type of sensing gives a linear relationship between the current and the analyte concentration. Figure 2.15 shows a limitingcurrent-type sensor. This has a pumping electrode in an enclosure having a small aperture for the diffusion of gases into the enclosure. The electrode inside the enclosure is negatively charged and the other electrode on the outer surface is positively charged. This converts the oxygen molecules to ions at the inner surface and makes these ions to be transported to the outer electrode through the oxygen vacancies in the YSZ electrolyte. Due to the oxidation and reduction reactions happening at the outer and inner electrodes respectively, a current is generated across the electrodes. This current can be used as a sensing signal for determining the concentration of the analyte gas.

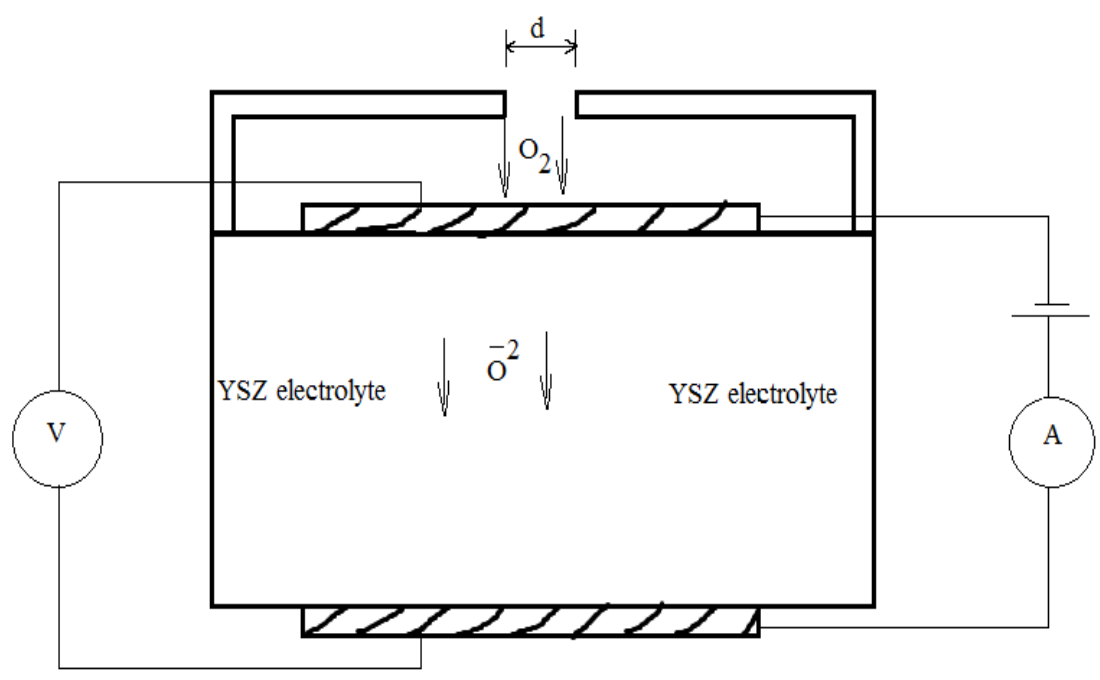

Figure 2.15: Typical structure of an amperometric sensor

Gradually, when a voltage between $0.5 \mathrm{~V}$ and $1.5 \mathrm{~V}$ is applied across the electrodes, the oxygen partial pressure at the cathode will approach zero. This is because; as the voltage applied across the electrodes increases, the $\mathrm{O}^{-2}$ ion formation and transport through the vacancies in the YSZ lattice also increases due to which the current generated also increases linearly (zone I of Figure 2.16). And then it reaches a point where the voltage applied is sufficient enough to fill all the 
vacancies in the YSZ lattice with oxygen ions that are getting transported from enclosure. Now, the partial pressure at the cathode approaches zero and the current generated becomes steady (zone II). This can be interpreted from Figure 2.16. If the voltage is still increased, the oxygen ions in the YSZ substrate dissociate from the lattice and move towards the outer electrode which results in further increase in current (zone III of Figure 2.16).



Figure 2.16: The response of a typical amperometric sensor (30).

An amperometric oxygen sensor is typically operated in zone II. There are two types of amperometric sensors

1) In which bulk diffusion occurs

2) Knudsen diffusion process in which the aperture is very small that the wall collisions of the gas molecules also play a role in obtaining the diffusion current.

For the bulk diffusion aperture the limiting current generated by the amperometric sensor is

$i_{\lim }=\frac{-4 F D_{O_{2}} P_{T}}{R T l} \ln \left(1-X_{O_{2}}\right)$

Where $l, F, P_{T}$ are the length of the diffusion hole, Faraday constant, total pressure in the ambient, $X_{\mathrm{O}_{2}}$ is the mole fraction of oxygen molecules and $\mathrm{D}_{\mathrm{O}_{2}}$ is the bulk diffusivity.

For Knudsen diffusion process the limiting current is

$i_{\lim }=\frac{-4 F D_{O_{2}} P_{T}}{R T l} X_{O_{2}}$. This shows that the limiting current is linear proportionality to the concentration of the oxygen molecules. 
Apart from oxygen, amperometric sensors are used to detect $\mathrm{NO}_{\mathrm{x}}$ as at higher oxygen concentrations. H. Jin et al (48). With $50 \mathrm{mV}$ DC voltage between the electrodes in a tubular model sensor cell shown in Figure 2.17 (a), the amperometric type of configuration could successfully detect $\mathrm{NO}_{2}$ in a range of $20-200 \mathrm{ppm} \mathrm{NO}_{2}$ at $550^{\circ} \mathrm{C}$.
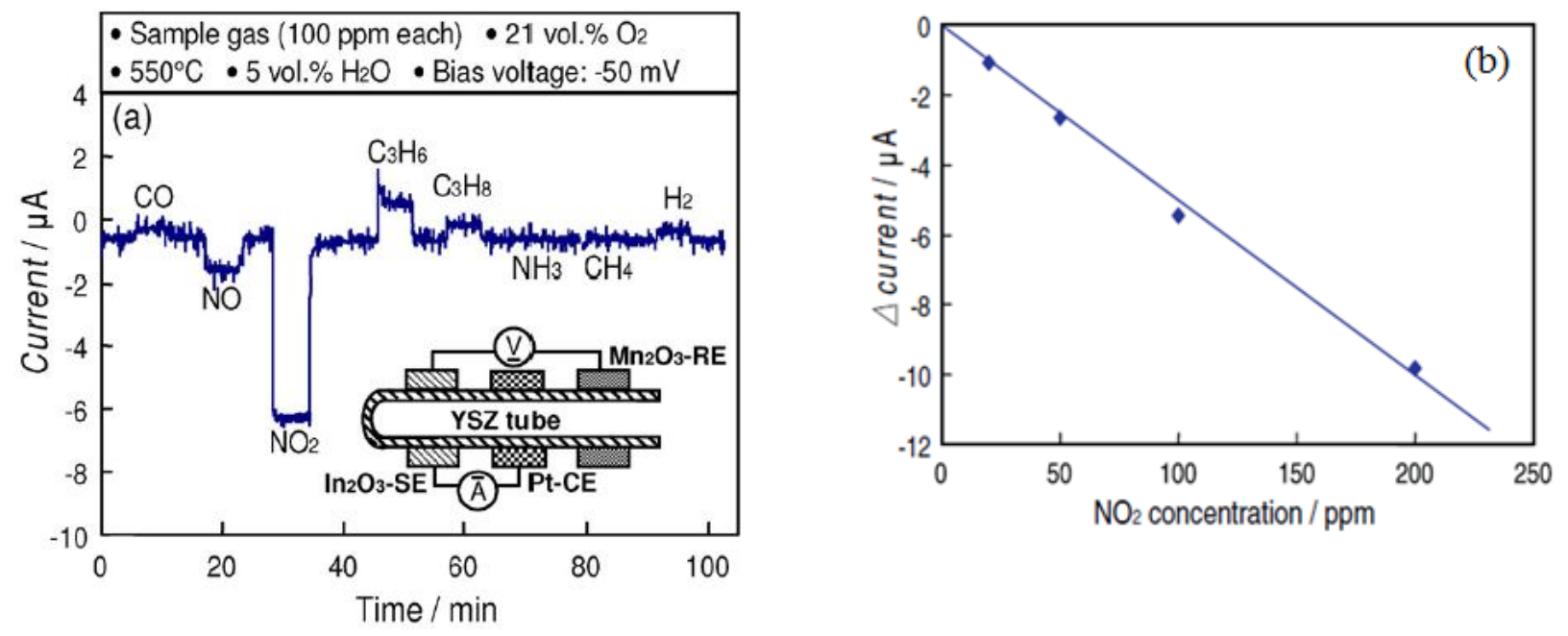

Figure 2.17: (a) Amperometric response to various gases and inset showing the cell configuration (b) Linear response to $\mathrm{NO}_{2}$ concentration in ppm (48)

Table 2.2: Brief overview of different amperometric sensors developed for various gases

\begin{tabular}{|l|l|l|l|l|l|}
\hline $\begin{array}{l}\text { Gases } \\
\text { detected }\end{array}$ & $\begin{array}{l}\text { Cell Structure } \\
\text { gas, electrode RE/YSZ/electrode SE, } \\
\text { gas }\end{array}$ & $\begin{array}{l}\text { Temperature } \\
\left({ }^{\circ} \mathrm{C}\right)\end{array}$ & $\begin{array}{l}\text { Concentration } \\
\text { range (in ppm) }\end{array}$ & Year & Ref. \\
\hline $\mathrm{CO}$ & $\begin{array}{l}\text { Air+CO, Pt/ScSZ/ITO, air+CO } \\
\text { Air }+\mathrm{CO}, \\
\mathrm{Au}(\mathrm{ITO} / \mathrm{LSGM} / \mathrm{LSC}(\mathrm{RuO} 2), \\
\text { air+CO }\end{array}$ & 600 & $0-500$ & 2007 & $(49)$ \\
\hline NOx & $\begin{array}{l}\text { Air+NO} \\
\text { air+NO }, \mathrm{Pt} / \mathrm{YSZ} / \mathrm{RhPtAu},\end{array}$ & $550-600$ & $200-1200$ & 2005 & $(51)$ \\
\hline HC's( $\left.\mathrm{C}_{3} \mathrm{H}_{6}\right)$ & Air, $\mathrm{Pt} / \mathrm{YSZ} / \mathrm{ZnO}(\mathrm{Pt})$, air+C $\mathrm{C}_{3} \mathrm{H}_{6}$ & 600 & $0-200$ & 2007 & $(52)$ \\
\hline
\end{tabular}




\subsubsection{Impedance metric}

This is another type of solid-state electrochemical gas sensors where a change in impedance of the sensor cell due to change in the gas concentration is measured as the sensing signal. For instance $\mathrm{N}$. Wu et al investigated the impedance change of a sensor cell Pt/YSZ/Au- $\mathrm{Ga}_{2} \mathrm{O}_{3}$ to a change in CO concentration which is shown in Figure 2.18 (a) (53). To interpret the impedance change, an equivalent circuit for the sensor device is generally employed which is shown in
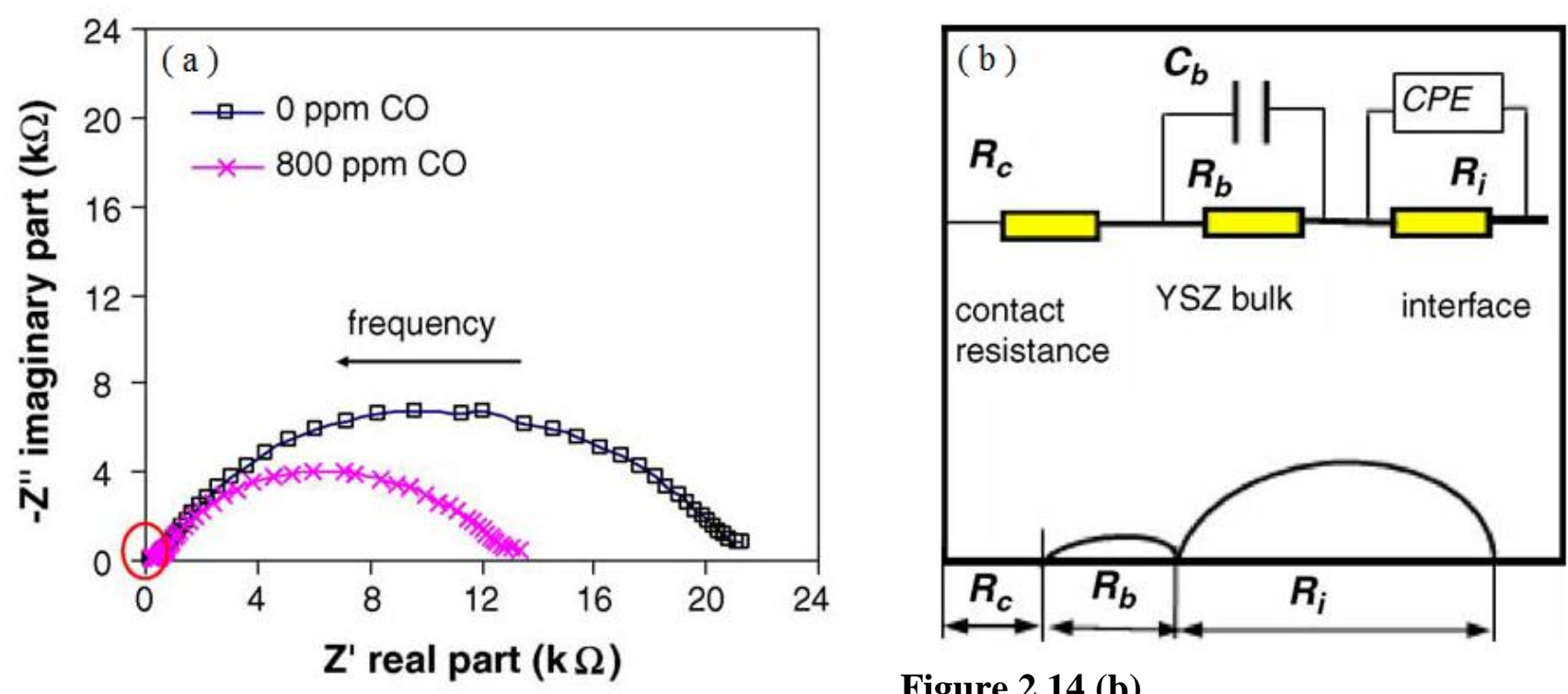

Figure 2.14 (b).

Figure 2.18: Impedance plot showing the sensor response to the presence of CO (53)

Here, Rc is the ohmic contact resistance of the cell, the RC elements present represent the resistance and capacitance of YSZ bulk and electrode/electrolyte interface respectively. The smaller and bigger arcs in Figure 2.18 (b) correspond to YSZ bulk electrolyte and the electrode/electrolyte interface respectively. With the introduction of $800 \mathrm{ppm} \mathrm{CO}$ the interfacial resistance reduced from $20.6 \mathrm{k} \Omega$ to $12.4 \mathrm{k} \Omega$, whereas there is no considerable change in the resistance of other elements in the configuration. Hence, only the electrode/electrolyte interface is sensitive to $\mathrm{CO}$ oxidation, which is shown in the response where the arc at low frequencies that corresponds to electrode/electrolyte interface is pulled down towards the real axis. At low 
frequency region (from $0.1 \mathrm{~Hz}$ to several $\mathrm{Hz}$ ), there is predominant effect of charge transfer on the sensitivity of the sensor. Hence, the researchers chose $0.42 \mathrm{~Hz}$ and performed the sensitivity test for detecting $\mathrm{CO}$. Impedancemetric sensor operations for the detection of gases like $\mathrm{NO}_{\mathrm{x}}$ (54), (55), HC's (56), CO (53) and water vapor (57) have been reported in literature. Table 2.3 summarizes the impedancemetric sensors for detecting various gases.

Table 2.3: Brief overview of different impedancemetric sensors developed for various gases

\begin{tabular}{|l|l|l|l|l|l|}
\hline $\begin{array}{l}\text { Gases } \\
\text { detected }\end{array}$ & Cell Structure & $\begin{array}{l}\text { Temperature } \\
\text { of operation } \\
\left({ }^{\circ} \mathbf{C}\right)\end{array}$ & $\begin{array}{l}\text { Concentration } \\
\text { range and gases } \\
\text { detected } \\
\text { ppm })\end{array}$ & Year & Reference \\
\hline $\mathrm{CO}$ & $\begin{array}{l}\text { Air+CO, } \\
\mathrm{Pt} / \mathrm{YSZ} / \mathrm{Au}- \\
\text { Ga2O3, air+CO }\end{array}$ & 550 & $0-800$ & 2005 & $(53)$ \\
\hline $\mathrm{NO}_{\mathrm{x}}$ & $\begin{array}{l}\text { Air, } \\
\mathrm{Pt} / \mathrm{YSZ} / \mathrm{ZnCr} 2 \mathrm{O} 4, \\
\text { air+NOx }\end{array}$ & $600-700$ & $50-400$ & 2002 & $(54)$ \\
\hline $\mathrm{HC}$ 's & $\begin{array}{l}\text { Air, } \\
\mathrm{Pt} / \mathrm{YSZ} / \mathrm{ZnO}(\mathrm{Pt}), \\
\text { air+HC's }\end{array}$ & 600 & $10-800 \mathrm{ppm}$ & 2006 & $(58)$ \\
\hline
\end{tabular}

\subsection{One-dimensional nanomaterials based sensors}

The gas sensing is mainly dependent on the type of materials used. But to improve the performance, the structure of the electrodes also has to be optimized for better results. Many kinds of materials have been investigated to see the effect of structure of electrodes on their gas sensing properties. It was found that with the increase in the surface area, the sensing properties have also improved (59), (60). One-dimensional nano materials have gained interest due to their better sensing properties compared to their bulk counterparts (61), (62). Particularly, one- 
dimensional (1-D) nanostructures (e.g., nanowires, nanofibers, nanorods, nanobelts and nanotubes) have received increased attention due to their high specific surface area (63), (64) and fast charge transport properties (65), (66), (67), (68). Sensing performance has been proved to be improved by incorporation of nanomaterials into sensors (69), (70), (71), (72). Many techniques like sol-gel (73), arc plasma method (74) etc. have been employed to fabricate the nanostructures which showed improved surface area and in turn improved sensing properties. Electrospinning has been found to be efficient and relatively simple way for fabricating nanofibers with uniform diameters and in large scale (75), (76). In this process a high voltage is applied between the syringe containing the polymer solution of the nanofiber material and a collector as shown in Figure 2.19.

Using a pump the polymer solution is slowly ejected from the syringe in few $\mathrm{ml} /$ hour. Due to the strong potential applied between the syringe and the collector, the polymer solution that comes out of the syringe is distorted into a conical shape that finally breaks up into tiny droplets and gets collected on the collector. These fibers can be further collected from the collector surface and heat treated to form the required crystalline phase that suits the application.

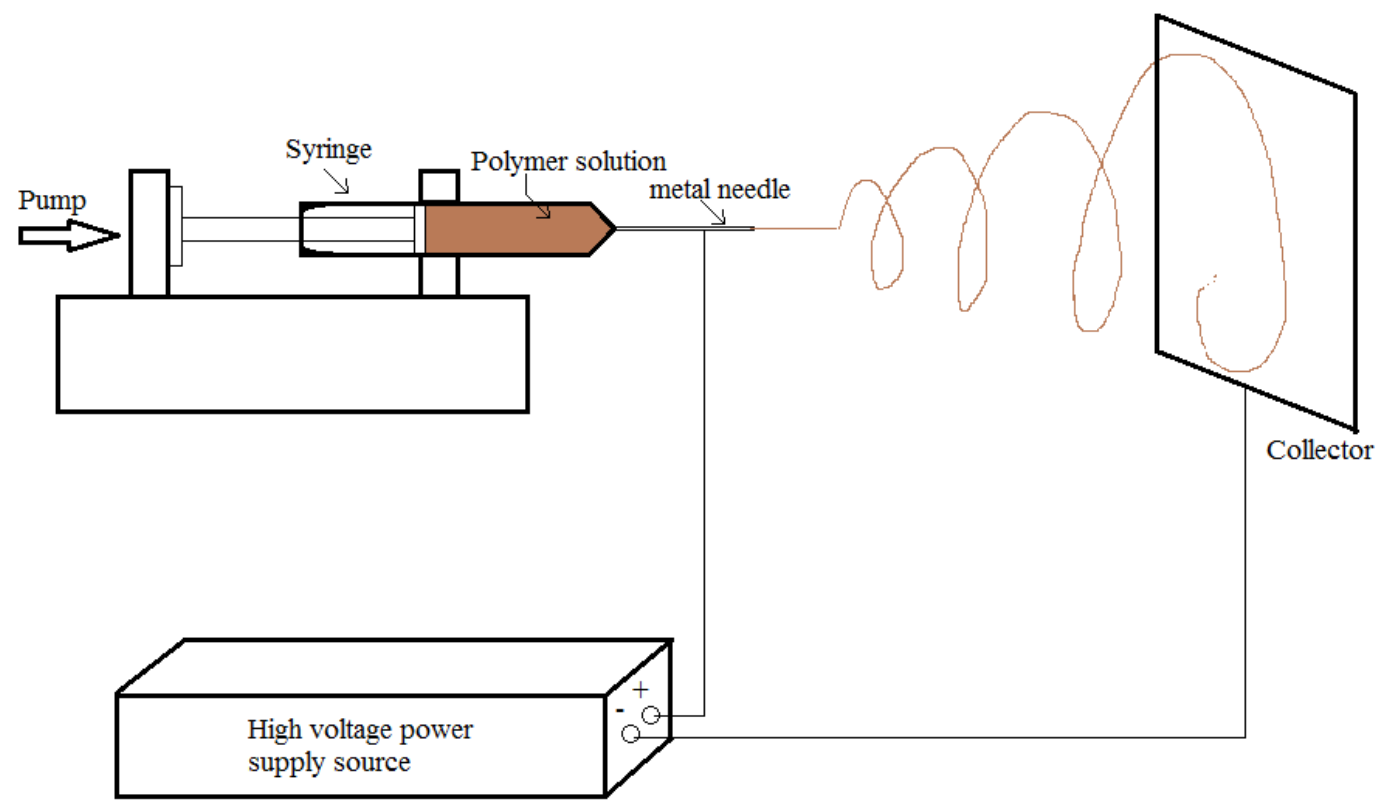

Figure 2.19: Schematic of electrospinning nanofibers

The nanofibers fabricated through electrospinning were found to have improved surface area upto 2 times compared to thin films and were successfully applied in dye-synthesized solar cells 
(77), catalysis (78), filtration (79) etc. The sensors fabricated using nanofibers as sensor elements were able to detect several gases like $\mathrm{CO}, \mathrm{NH}_{3}, \mathrm{NO}_{2}, \mathrm{CO}_{2}$ and volatile organic compounds (VOC like $\mathrm{CH}_{3} \mathrm{OH}, \mathrm{C}_{2} \mathrm{H}_{5} \mathrm{OH}, \mathrm{C}_{5} \mathrm{H}_{10} \mathrm{Cl}_{2}$ etc) shown in Table 2.4 with better sensing properties compared to thin films.

Table 2.4 Sensor types, temperature of operation and their detection limits (62)

\begin{tabular}{|l|l|l|l|l|l|l|}
\hline $\begin{array}{l}\text { Sensor } \\
\text { type }\end{array}$ & Material used & $\begin{array}{l}\text { Gases } \\
\text { tested }\end{array}$ & $\begin{array}{l}\text { Detection } \\
\text { limit }\end{array}$ & Temperature & Ref & Year \\
\hline $\begin{array}{l}\text { Surface } \\
\text { Acoustic } \\
\text { Wave } \\
\text { (SAW) }\end{array}$ & Poly Acrylic Acid & $\mathrm{NH}_{3}$ & $50 \mathrm{ppm}$ & Room temperature & $(80)$ & 2004 \\
\hline Resistive & Carbon black & $\mathrm{CH}_{3} \mathrm{OH}$ & $1000 \mathrm{ppm}$ & Room temperature & $(82)$ & 2006 \\
& $\begin{array}{l}\text { SnO } \\
\text { Carbon black }\end{array}$ & $\mathrm{C}_{2} \mathrm{H}_{5} \mathrm{OH}$ & $10 \mathrm{ppb}$ & $330{ }^{\circ} \mathrm{C}$ & $(83)$ & 2008 \\
$\mathrm{C}_{5} \mathrm{H}_{10} \mathrm{Cl}{ }_{2}$ & $5 \mathrm{ppm}$ & Room temperature & $(82)$ & 2006 \\
\hline
\end{tabular}

The nanofibrous electrodes for high temperature electrochemical applications exhibited enhanced electro-catalytic activity and displayed better charge transport properties compared to conventional micron-sized powder electrodes (68), (67). In addition to this, the nanofibrous sensing electrode exhibited good thermal stability at $750{ }^{\circ} \mathrm{C}$. (68). So in this thesis, nanofibers based sensing electrodes are proposed to be fabricated and tested for their $\mathrm{CO}$ gas sensing properties at high temperature environment $\left(>500{ }^{\circ} \mathrm{C}\right)$. 


\subsection{Summary}

This chapter has reviewed the existing technologies like SAW, IR, gas chromatography and semiconducting techniques to measure the $\mathrm{CO}$ gas concentration. Also, a detailed explanation of the working principle of a mixed-potential type gas sensor along with the theory behind its operation has been presented. Several existing materials that act as sensing electrode materials in the solid-state gas sensing have been reviewed. It is understood that nanofibers possess higher specific surface area than the conventional bulk counterparts and hence show improved sensing properties towards gas detection. So, the sensing electrodes in the mixed-potential sensors are proposed to be fabricated using nanofibers and further tested for their sensing properties toward CO gas detection. 


\section{Chapter 3: Experimental Investigation of Nanofibrous $\mathrm{La}_{0.8} \mathrm{Sr}_{0.2} \mathrm{MnO}_{3}$ Electrode for Gas Sensing}

\subsection{Introduction}

Solid-state chemical sensors are typically categorized into two types according to their sensing principle, resistive type (62), (70), (87), (88), (89), (90) electrochemical sensing type (22), (53), (69). The resistive sensors made of polymers are not suited at high temperatures (87), (88), (89). Similarly, the resistive sensors based on metal oxide semiconductors which operate on gas adsorption/desorption and alteration of depletion zone near the metal oxide, are also not attractive for high temperatures $\left(>400{ }^{\circ} \mathrm{C}\right)$ as desorption dominates at elevated temperatures (62), (90). Therefore, compared to resistive type sensors, electrochemical sensors based on solid-state electrolytes are more attractive for high temperature applications $\left(>500{ }^{\circ} \mathrm{C}\right)$.

In this research, electrospun $\mathrm{La}_{0.8} \mathrm{Sr}_{0.2} \mathrm{MnO}_{3}$ (LSM) nanofibers have been chosen as the sensing electrode material in a planar sensor configuration with platinum $(\mathrm{Pt})$ as the counter electrode. LSM is selected as the sensing electrode material because, apart from being compatible with YSZ electrolyte, $\mathrm{LaMnO}_{3}$ is reported to have good selectivity for $\mathrm{CO}$ oxidation (91), (92). Also, partial doping of $\mathrm{Sr}$ into La site with an optimized composition of $\mathrm{La}_{0.8} \mathrm{Sr}_{0.2} \mathrm{MnO}_{3}$ improves the sensitivity of material towards CO gas sensing (93). Added to this, the thermal expansion coefficient of LSM matches well with YSZ, which helps in maintaining thermal stability of the sensing electrode at high temperatures (91), (92). The nanofibrous structure forms a highly porous network, which facilitates the transport of gas in the sensing electrode. In addition, the long LSM nanofibers can also provide continuous pathway for charge transport. Added to this, the nanofibers have higher specific surface area than conventional micron-sized powders, which will provide more active reaction sites for electrochemical oxidation of $\mathrm{CO}$. It is therefore believed that such a nanofibrous electrode shows better performance for $\mathrm{CO}$ gas sensing in terms of limit of detection (LOD) and response time compared to the conventional micron-sized powder electrode. 


\subsection{Experimental setup}

To test a sensor sample for its performance in high temperature environment, equipment which mimics the combustion environment is required. Figure 3.1 shows a graphic of the testing equipment that was employed in the present work. The sensor was placed in a quartz tube in a furnace while testing the $\mathrm{CO}$ sensing properties. The simulated air $\left(79 \mathrm{vol} \% \mathrm{~N}_{2}+21 \mathrm{vol} \% \mathrm{O}_{2}\right)$ mixed with various concentrations of $\mathrm{CO}$ was fed into the quartz tube at a flow rate of $200 \mathrm{ml}$ $\min ^{-1}$. The signal generated from the sensor was recorded with Solartron 1860/1897 electrochemical interface and impedance analyzer at an open circuit condition. Impedance data were collected at $\mathrm{AC}$ amplitude of $10 \mathrm{mV}$ from $1 \mathrm{M} \mathrm{Hz}$ to $0.1 \mathrm{~Hz}$. The data was analyzed with the Cview ${ }^{\circledR}$ and Zview ${ }^{\circledR}$ software.

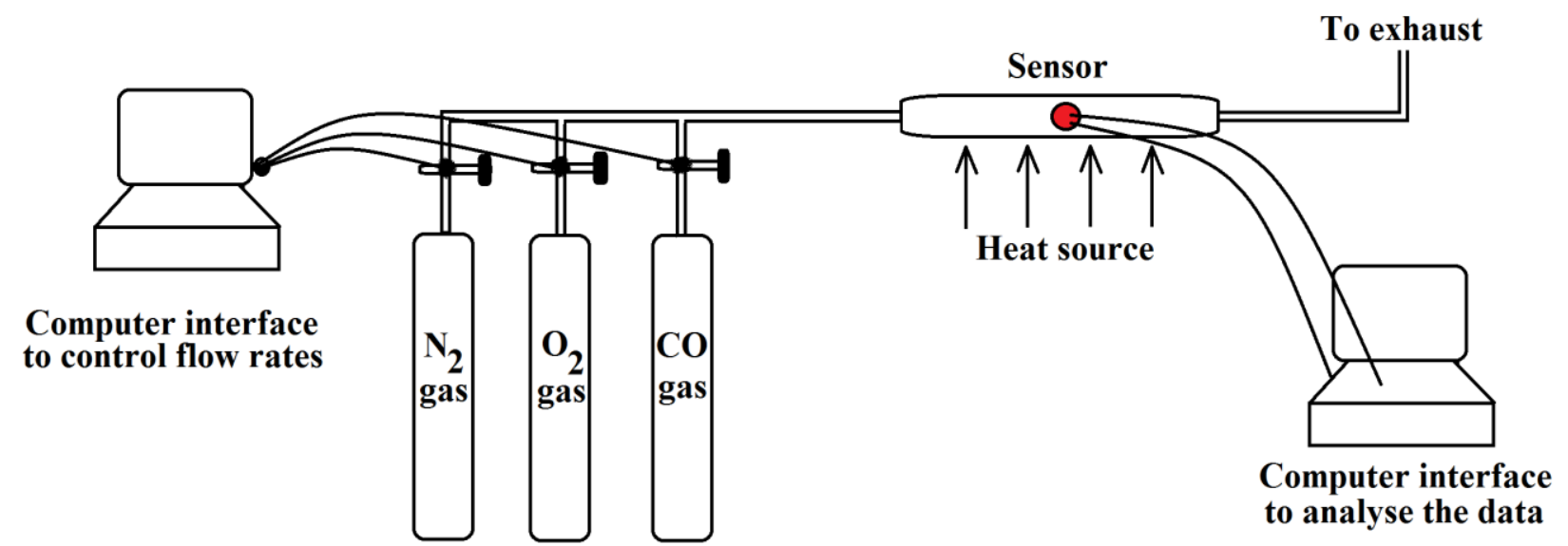

Figure 3.1: Graphic of the testing equipment to mimic the combustion environment. 


\subsection{Precursor preparation and electrospinning}

The LSM nanofibers were prepared by electrospinning method. Figure 3.2 shows the experimental apparatus used for electrospinning the $\mathrm{La}_{0.8} \mathrm{Sr}_{0.2} \mathrm{MnO}_{3}$ nanofibers. First, $6 \mathrm{wt} \%$ of polyacrylonitrile (PAN) was dissolved in N'N"-dimethylformamide (DMF) at $60{ }^{\circ} \mathrm{C}$. Then, $\mathrm{La}\left(\mathrm{CH}_{3} \mathrm{COO}\right)_{3} \bullet 1.5 \mathrm{H}_{2} \mathrm{O}, \mathrm{Sr}\left(\mathrm{CH}_{3} \mathrm{COO}\right)_{2} \bullet 0.5 \mathrm{H}_{2} \mathrm{O}$ and $\mathrm{Mn}\left(\mathrm{CH}_{3} \mathrm{COO}\right)_{2} \bullet 4 \mathrm{H}_{2} \mathrm{O}$ were added into the solution in 4:1:5 mole ratio. By doing so, the total cation concentration in the precursor becomes $0.5 \mathrm{M}$. The solution was further stirred until a black transparent precursor was formed. Then, this precursor was loaded into a syringe `with 25 gauge needle and mounted on a syringe pump (New Era 1000) (shown in Figure 3.3). The syringe needle was connected to the positive end of the power supply and a piece of stainless steel foil which is used for collecting the nanofibers is grounded.

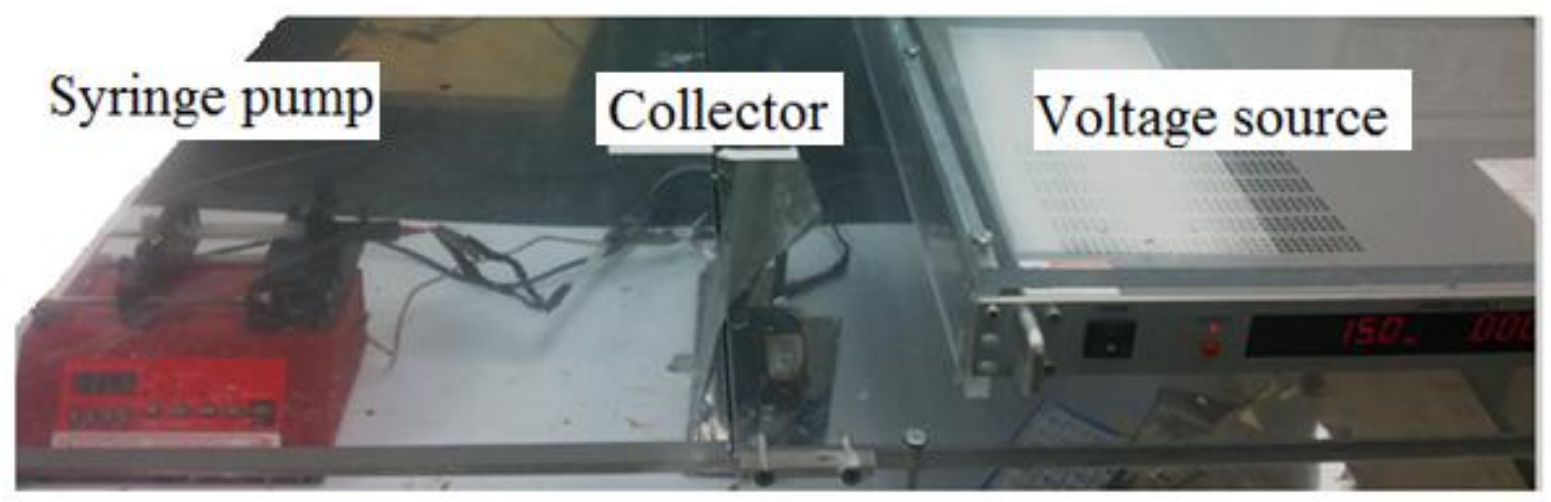

Figure 3.2: Experimental setup for electrospinning LSM nanofibers.

Figure 3.3: New ERA 1000 syringe pump

To obtain uniformity in the diameters of the nanofibers, the electrospinning process has to

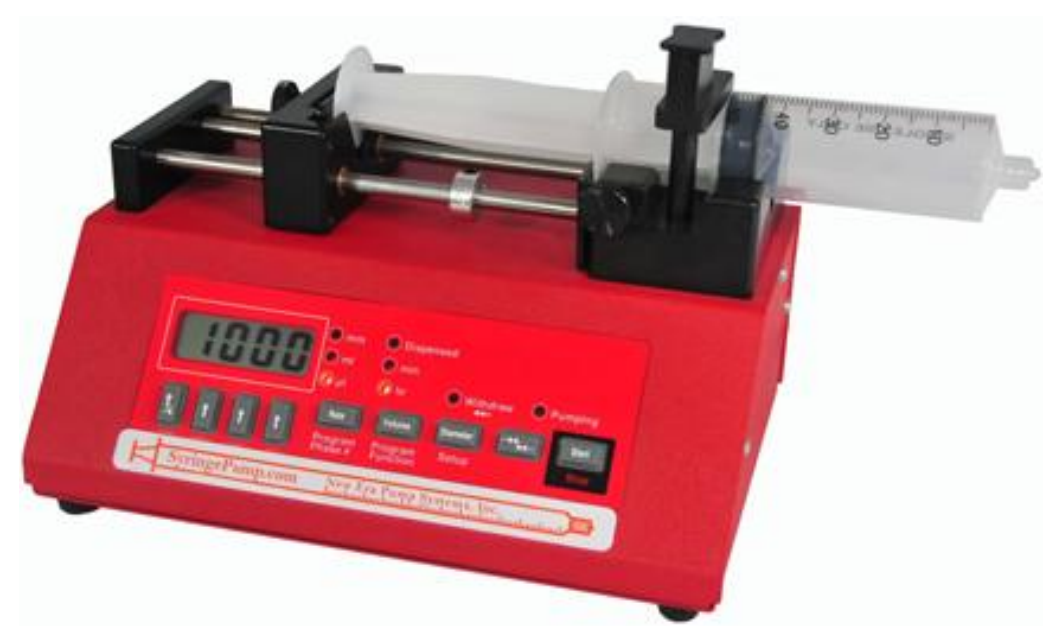


be optimized in terms of flow rate, distance between the needle and the collector, and the magnitude of electric field applied. After several experiments, it was deduced that the following parameters are needed to obtain fine nanofibers.

1) The distance between the tip of the needle and the stainless steel foil has to be $15 \mathrm{~cm}$

2) A high voltage of $18 \mathrm{kV}$ has to be applied between the needle and the collector.

3) The precursor should be injected into the electrical field with a flow rate of $0.25 \mathrm{ml} / \mathrm{hr}$.

By doing so, the precursor was broken into tiny droplets which form fine nanofibers and get collected on the steel foil. These nanofibers were heated at $600{ }^{\circ} \mathrm{C}$ to burn off the organic compounds as well as to crystallize the LSM phase. Figure 3.4 gives a flow chart of fabricating the nanofibers.



Figure 3.4: Flow chart of nanofiber preparation process

\subsection{Sensor fabrication}

A planar configuration was adopted for fabricating the gas sensor. Fabrication process of the sensors is shown in Figure 3.5. First the Pt paste (Alfa Aesar) was pasted symmetrically on either sides of the YSZ disc and then the Pt wires are embedded into them. These electrodes are sintered at $950{ }^{\circ} \mathrm{C}$ for 3 hours. A paste made of LSM nanofibers and terpineol (in 1:2 ratio) was then casted on one Pt electrode and sintered at $1050{ }^{\circ} \mathrm{C}$ for 3 hours which served as the sensing electrode. Similarly, another sensor was prepared using LSM powders $\left(\mathrm{La}_{0.8} \mathrm{Sr}_{0.2} \mathrm{MnO}_{3}, \mathrm{Nextech}\right.$ Materials) for comparison. 


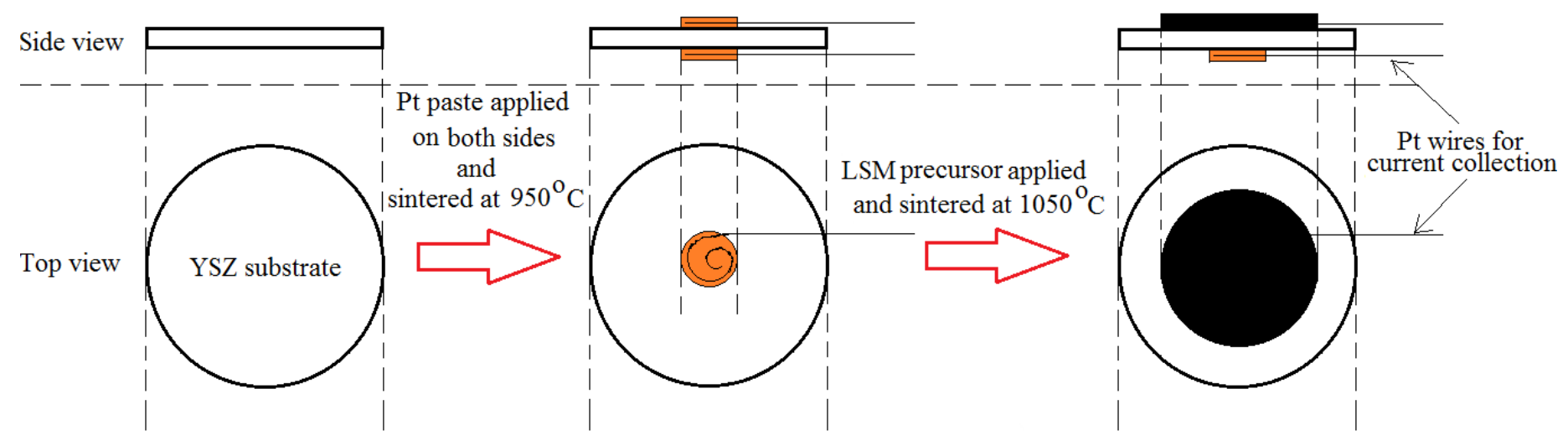

Figure 3.5: Fabrication of a sensor

After fabrication, the gas sensing property of the sensor was examined in a tube furnace with controlled temperatures and atmospheres as detailed in section 3.1. Figure 3.6 shows a sensor which was tested for its response characteristics in high temperature environment. The LSM SE was intact and showed good attachment to the YSZ substrate.

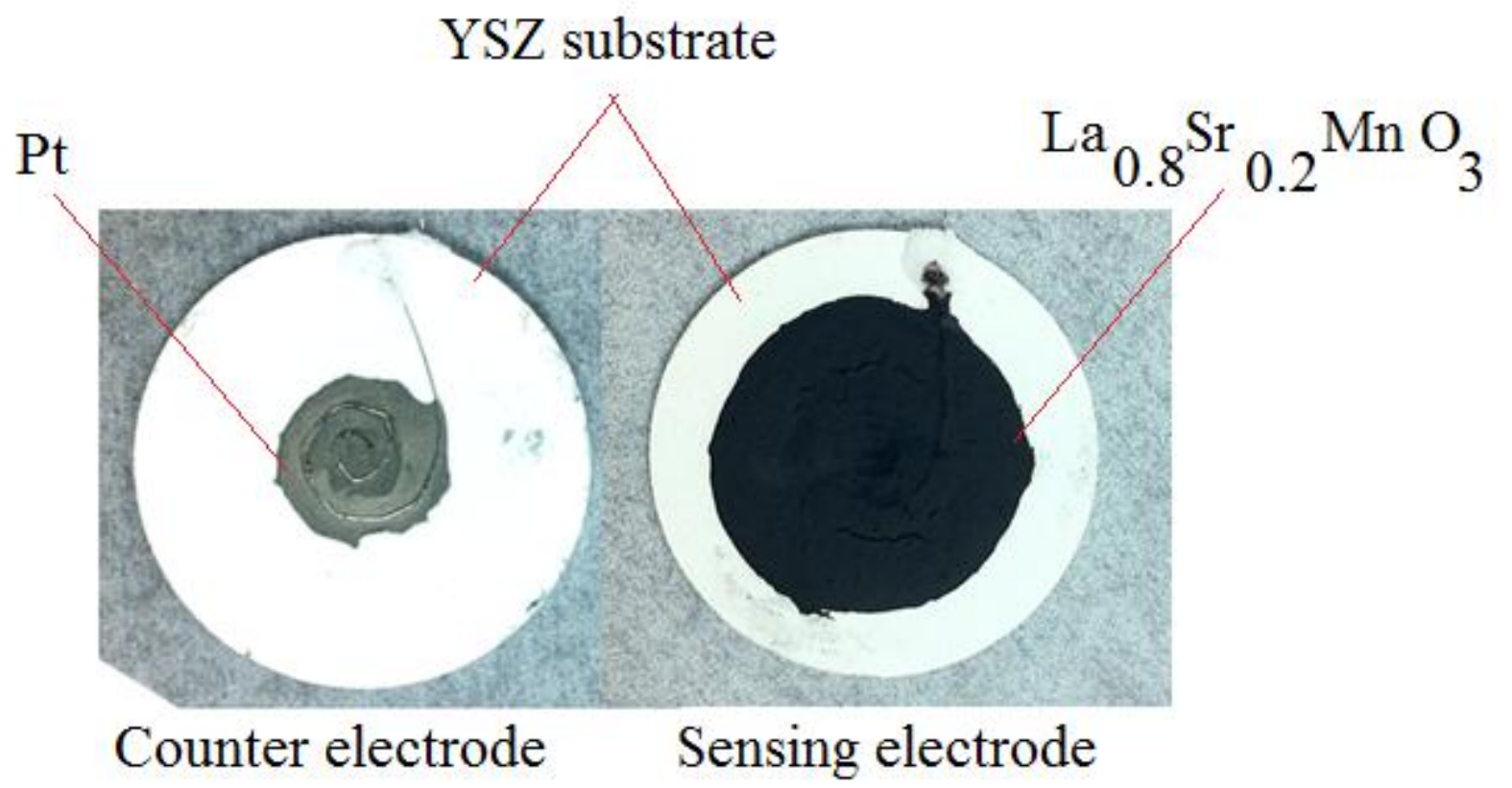

Figure 3.6: A tested sample with $\mathrm{Pt}$ counter electrode and $\mathrm{La}_{0.8} \mathrm{Sr}_{0.2} \mathrm{MnO}_{3}$ sensing electrode on either side of YSZ substrate 


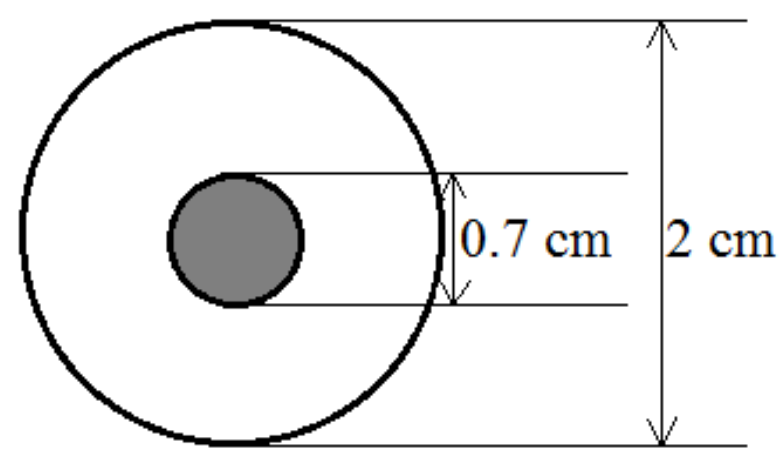

Counter electrode side



Sensing electrode side

Figure 3.7: The dimensions of sensing and counter electrodes on the YSZ substrate

The dimensions of the counter electrode and the sensing electrode are shown in Figure 3.7. The diameter of the sensing electrode $(1.4 \mathrm{~cm})$ is twice that of the counter electrode $(0.7 \mathrm{~cm})$ which can also be seen in Figure 3.6.

\subsection{Materials characterization}

Figure 3.8(a) shows the surface morphology of the LSM nanofiber electrode. It can be seen that the nanofiber structure was retained even after sintering at $1050{ }^{\circ} \mathrm{C}$ for $3 \mathrm{~h}$. The diameters of individual nanofibers were $150-225 \mathrm{~nm}$ and were up to tens of micrometers in length. It is evident that these nanofibers were interlaced to form a porous network electrode. Each nanofiber was composed of grains which are about $150 \mathrm{~nm}$ in size. Each nanofiber could reach up to several micrometers in length. Figure 3.8 (c) shows the surface morphology of powder LSM electrode. Here, the particle size ranges from $200 \mathrm{~nm}$ to $3 \mu \mathrm{m}$. The surface area for the LSM nanofibers and powders were measured to be $10.93 \mathrm{~m}^{2} / \mathrm{g}$ and $5.78 \mathrm{~m}^{2} / \mathrm{g}$, respectively. This evinces that there was an increase in surface area of the electrode due to the presence of nanofibers and better porous structure compared to the electrode made of bulk LSM powders. Figure 3.8 (d) is the XRD pattern of the LSM nanofibers after heating at $1050{ }^{\circ} \mathrm{C}$, showing all the diffraction peaks indexed well with $\mathrm{La}_{0.8} \mathrm{Sr}_{0.2} \mathrm{MnO}_{3}$, which confirmed the phase integrity of LSM nanofibers toward thermal stability. The better porosity of nanofibers compared to bulk powder electrodes had several effects on the sensing performance of the sensors towards CO gas. 

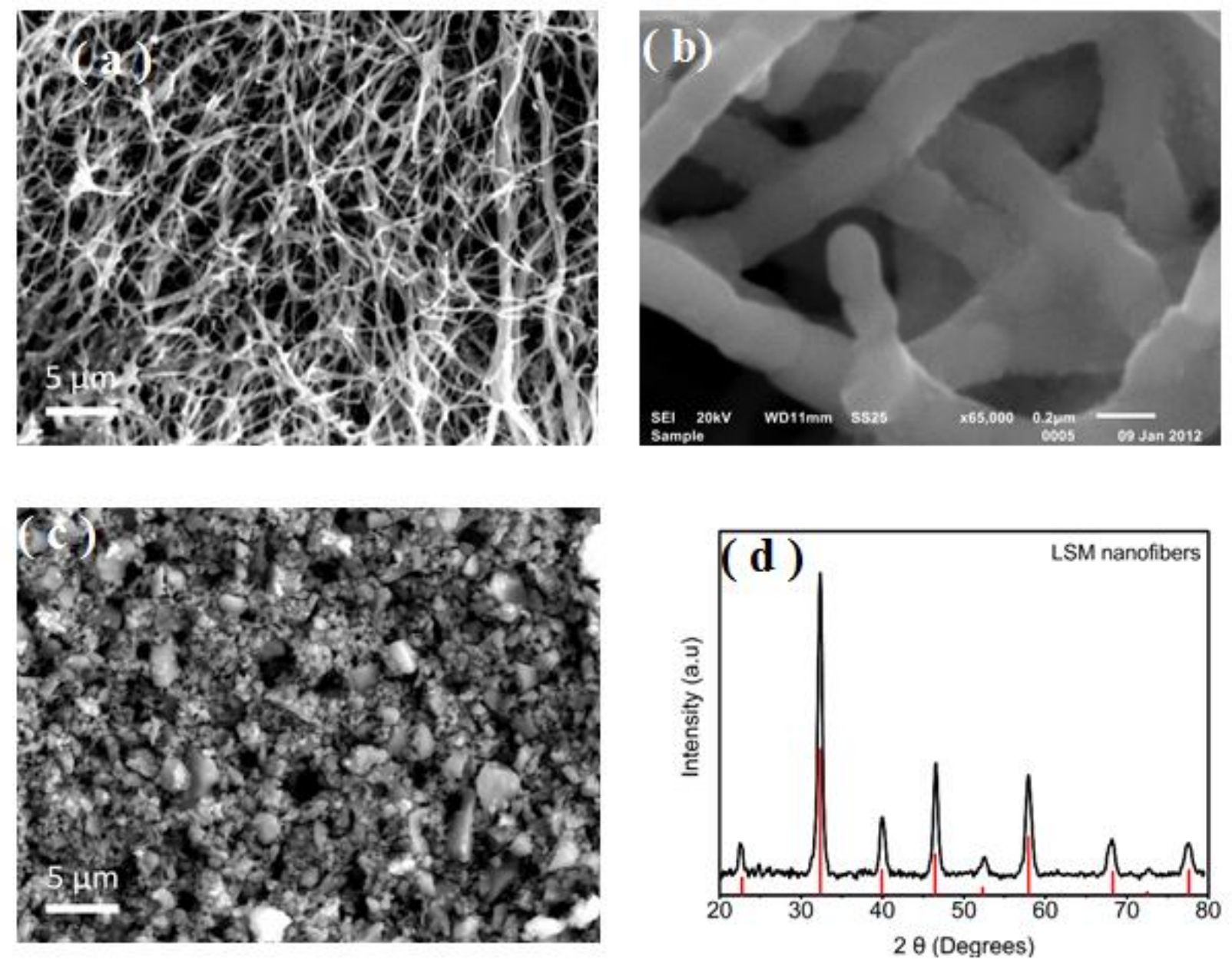

Figure 3.8: (a), (b) SEM images of the LSM nanofiber sensing electrode (after sintering at $1050{ }^{\circ} \mathrm{C}$ for 3 hours), (c) SEM image of the LSM powder sensing electrode and (d) the XRD pattern of the LSM nanofibers after heating at $1050{ }^{\circ} \mathrm{C}$ along with standard diffraction pattern.

\subsection{Gas sensing results}

When the sensor was exposed to $\mathrm{CO}$, an electromotive force (EMF) was built between the sensing and the counter electrodes based on the mixed potential theory (94). On the Pt counter electrode, oxygen molecules were reduced to oxygen ions:

$$
\mathrm{O}_{2}+4 \mathrm{e}^{-}=2 \mathrm{O}^{2-}
$$


These oxygen ions transported through the solid YSZ electrolyte and reached the sensing electrode, where $\mathrm{CO}$ was oxidized to $\mathrm{CO}_{2}$ via the reaction below

$$
2 \mathrm{CO}+2 \mathrm{O}^{2-}=2 \mathrm{CO}_{2}+4 \mathrm{e}^{-} \quad 3.2
$$

The sensitivity experiment towards $\mathrm{CO}$ gas was examined at $550{ }^{\circ} \mathrm{C}$ and $600{ }^{\circ} \mathrm{C}$. Figure 3.9 (a) and (b) shows the sensitivity curves for the LSM nanofibers and commercial powder samples. It was observed that under steady air supply, both sensors showed stable background potential close to $1 \mathrm{mV}$. As soon as trace amounts of $\mathrm{CO}$ was introduced, an EMF was built between the sensing and the counter electrodes based on the mixed potential theory.

The mixed potential is highly dependent on the concentration of $\mathrm{CO}$ and the electrode activity towards $\mathrm{CO}$ oxidation as well as the microstructure of the sensing electrode. Figures 3.9 (c) and (d) show the EMF value as a function of the CO concentration for the LSM nanofiber and commercial powder samples at $550{ }^{\circ} \mathrm{C}$ and $600{ }^{\circ} \mathrm{C}$. The LSM nanofibers electrode showed higher EMF value compared to powder sample for the same $\mathrm{CO}$ concentration at $550{ }^{\circ} \mathrm{C}$ and $600{ }^{\circ} \mathrm{C}$. For example, the EMF for $100 \mathrm{ppm} \mathrm{CO}$ at $600{ }^{\circ} \mathrm{C}$ was $1.94 \mathrm{mV}$ for LSM nanofibers and 0.48 $\mathrm{mV}$ for powder sample. Also, the low detection limit for the LSM nanofibers sensor was $20 \mathrm{ppm}$ and $5 \mathrm{ppm}$ while the powder sample detection limit was $50 \mathrm{ppm}$ and $20 \mathrm{ppm}$ at $600{ }^{\circ} \mathrm{C}$ and 550 ${ }^{\circ} \mathrm{C}$ respectively. This indicates that nanofibers have significantly improved sensitivity as well as low detection limit, especially at high temperatures, which are key issues for on-line combustion process monitoring. The EMF for different $\mathrm{CO}$ concentrations is plotted in Figure 3.9 (c). A linear response region can be observed up to 500 ppm CO as shown in Figure 3.9 (d), beyond which a non-linear behavior was observed. It can be seen that the slopes of the linear calibration curves of the LSM nanofibers were 4 and 2.3 times higher than the powder sample at $600{ }^{\circ} \mathrm{C}$ and $550{ }^{\circ} \mathrm{C}$ respectively, which indicates that the sensitivity of LSM nanofibers based sample is high as compared to the bulk powders. It should be noted in the present study, that the EMF is linearly proportional to the $\mathrm{CO}$ concentration rather than logarithmic $\mathrm{CO}$ concentration reported elsewhere (41). Similar behavior has also been reported for other sensors in literature (94). For example, Pt/Ceria sensing electrode exhibited similar linear relationship to $\mathrm{CO}$ concentration at $600{ }^{\circ} \mathrm{C}$. The main reason is attributed to the different rate limiting processes for $\mathrm{CO}$ oxidation reactions (94). 
Figure 3.10 (a) represents the response transient curve for the LSM nanofiber and powder sensor samples at $550{ }^{\circ} \mathrm{C}$ for different concentrations of $\mathrm{CO}$. The response time which is defined as the time taken by the sensor to reach $90 \%$ of the statured signal is also an important merit for a gas sensor. Nanofibers sensor showed improved signal output compared with powder sample for the same CO concentration and which is consistent with the calibration curves. Moreover, the nanofiber sensor exhibited a faster response for $\mathrm{CO}$ compared to the powder sample. For instance, from Figure 3.10 (b) the response time of nanofiber sensor for $500 \mathrm{ppm} \mathrm{CO}$ was $55 \mathrm{~s}$ whereas the powder sample was 80s. In view of the microstructures of the sensing electrode, the highly porous nanofibers network accommodates for better gas diffusion into the active sites and enhances the sensing capability of the sensor and also reduces the response time. This is a major advantage for the one dimensional nanomaterials.
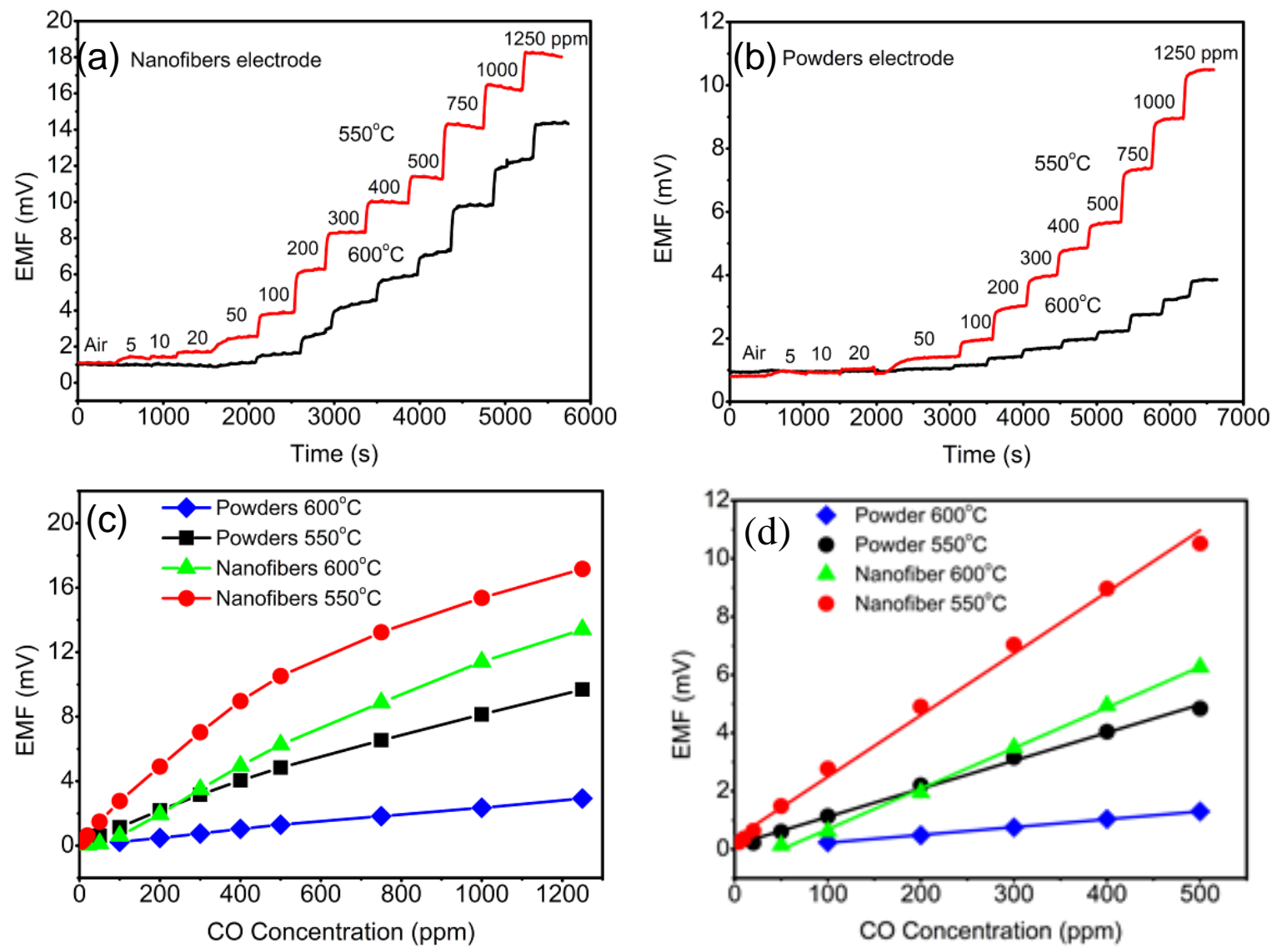

Figure 3.9: (a) Gas sensitivity curves of LSM nanofibers electrode; (b) Gas sensitivity curves of the LSM powders electrode; (c) Gas response curves of the nanofibers and powders electrode; (d) The linear calibration curve of the nanofibers and the powders electrode when the $\mathrm{CO}$ concentration ranged from $5 \mathrm{ppm}$ to $500 \mathrm{ppm}$. 

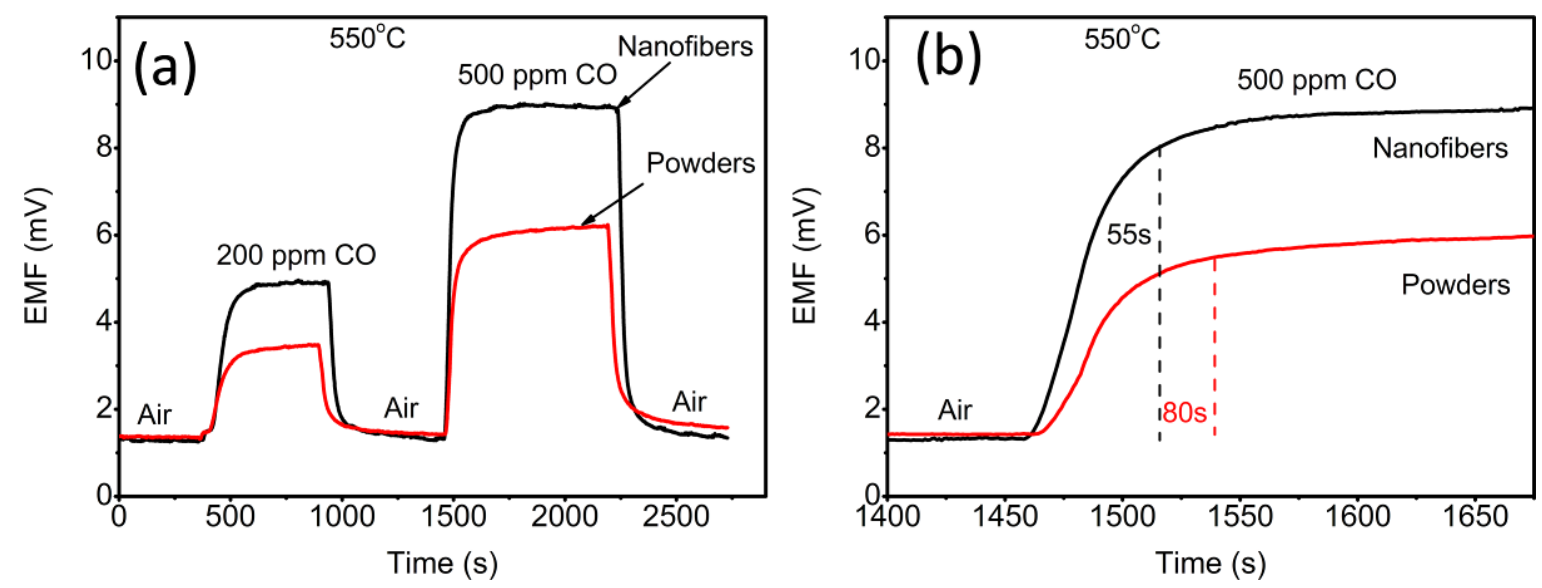

Figure 3.10: (a) Comparison of the response transients to $\mathrm{CO}$ at $550^{\circ} \mathrm{C}$ of the nanofibers electrode and the powder electrode, (b) is the detail response when the sensors exposed to 500 ppm CO

In order to better understand why the nanofiber sensor exhibited better sensing performance than the powder sensor, complex impedance measurement was performed. Figure 3.11 (a) shows the Nyquist plots obtained from the nanofiber and powder samples in synthetic air and mixture containing air with $500 \mathrm{ppm} \mathrm{CO}$ at $550{ }^{\circ} \mathrm{C}$. The applied DC bias was $0 \mathrm{mV}$. For both samples in air, a semicircle appeared at high frequency region (Figure 3.11 (b)), while a large tail appeared at low frequency region. It should be noted that the diameter of the arc for the nanofibers sensor is small, implying low impedance compared to the commercial powder sample. When $500 \mathrm{ppm}$ $\mathrm{CO}$ was introduced, there was no much change in the high frequency semicircle. However, the low frequency tail slightly shifted to low impedance region. Such observation is consisted with previously reported impedance metric gas sensors (53), (95), (96). An equivalent circuit was adopted to intercept the data. The schematic circuit model is shown in the inset of Figure 3.11 (a). The circuit consists a series resistance $(\mathrm{Rc})$, which represents the resistance from the ohmic resistance of YSZ electrolyte and the contact lead wires. A pair of constant phase elements (R$\mathrm{CPE})$ connected in parallel is used to represent the bulk oxide resistance $(\mathrm{Rb}-\mathrm{CPEb})$ and the interfacial or electrochemical reaction resistance ( $\mathrm{Ri}-\mathrm{CPEi}$ ) which involves the, respective charge transfer process. 

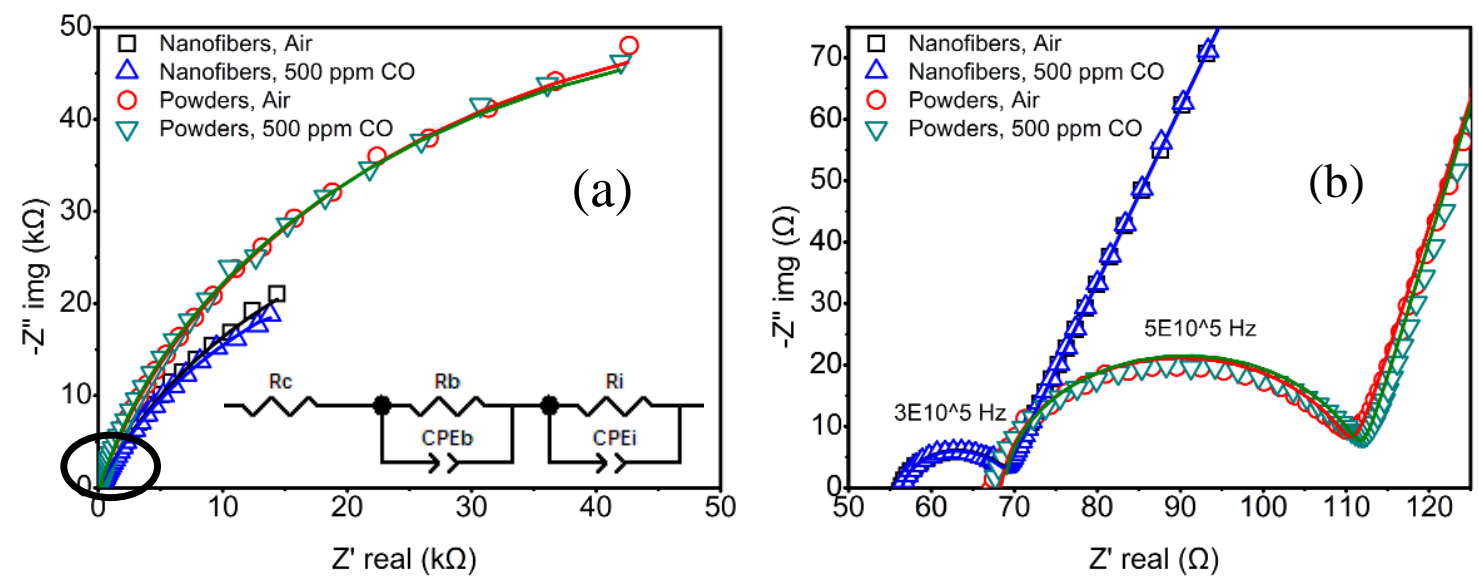

Figure 3.11: (a) Full range Nyquist Impedance spectra of the nanofibers and powders sensor taken at $550^{\circ} \mathrm{C}$ at open circuit, showing the effect of the presence of $\mathrm{CO}$, the inset is the model circuit for data fitting, (b) the detail of the circle zone in (a), the number is the characterization frequency of the semicircle. The open symbols are the measured data and the solid lines are fitted data

The impedance of the CPE is defined as $Z=i \omega(1 / Q)^{\mathrm{n}}$, in which $\omega$ is the radius speed, $\mathrm{Q}$ is the pseudo capacitance and $\mathrm{n}$ is the exponent constant. The fitting results of the impedance spectra are listed in Table 3.1. It can be seen that the nb is close to 1 and the Rb-CPEb kept almost constant before and after $\mathrm{CO}$ was introduced. The characterization frequency of the $\mathrm{Rb}-\mathrm{CPEb}$ was in the range of $10^{5} \mathrm{~Hz}$, whereas the pseudo capacitance of CPE1 was $10^{-7}-10^{-8} \mathrm{~F}$. These values were consistent with previously reported results and can be attributed to the bulk oxide electrode. In contrast, the Ri-CPEi pair was sensitive to the CO gas. For the LSM nanofibers electrode, the Ri value was reduced to $7.52 \mathrm{E} 4 \Omega$ when exposed to $\mathrm{CO}$ as compared with $8.75 \mathrm{E} 4$ $\Omega$ observed in air. The powder electrode showed a similar trend as Ri was reduced from 1.25E5 $\Omega$ to $1.19 \mathrm{E} 5 \Omega$. Based on these observations, it can be concluded that the $\mathrm{CO}$ oxidation process mainly occurring at the TPB's, which is the interface between the electrode, the electrolyte and the gas. The change in $\mathrm{Ri}$ could be used to estimate the charge transfer resistance due to electrochemical oxidation reaction of $\mathrm{CO}$. After exposure to $\mathrm{CO}$, the ratio of Ri decreased to $14 \%$ and $5 \%$ for nanofibers and powder sample, respectively. The above analysis has clearly demonstrated that the LSM nanofiber electrode had higher activity towards CO electrochemical oxidation compared with commercial powder sample. Such high activity leads to the higher EMF response due to higher CO concentration gradient in the LSM nanofibers matrix. 
The DC bias effect on the impedance spectra has also investigated in order to further verify the oxidation of $\mathrm{CO}$ via electrochemical reaction. It can be seen in Figure 3.12 that when $100 \mathrm{mV}$ and $300 \mathrm{mV}$ DC bias was applied to the nanofibers sensing electrode, a reduction of the interfacial resistance was observed while the oxide bulk resistance barely changed. The CO electrochemical oxidation reaction at the TPB is shown below:

$2 \mathrm{CO}+2 \mathrm{O}^{2-}=2 \mathrm{CO}_{2}+4 \mathrm{e}^{-}$

Here, the applied DC bias interrupted the reaction equilibrium and forced the $\mathrm{CO}$ electrochemical oxidation on the sensing electrode. Therefore, the charge transfer across the TPB was changed since the process related to charge transfer could be affected only by the applied DC bias. This confirms that the $\mathrm{CO}$ was electrochemically oxidized rather than pure catalytic oxidation

Table 3.1: The fitting results of the LSM nanofibers and powders sensors in air and in 500 ppm $\mathrm{CO}$ at $550{ }^{\circ} \mathrm{C}$

\begin{tabular}{|l|l|l|l|l|l|l|l|l|}
\hline Sample & $\mathbf{R}_{\mathbf{c}}(\mathbf{\Omega})$ & $\mathbf{R}_{\mathbf{b}}(\mathbf{\Omega})$ & $\mathbf{Q}_{\mathbf{b}}$ & $\mathbf{n}_{\mathbf{b}}$ & $\mathbf{R}_{\mathbf{i}}(\mathbf{\Omega})$ & $\mathbf{Q}_{\mathbf{i}}$ & $\mathbf{n}_{\mathbf{i}}$ & Fitting \\
& & & & & & & & \\
\hline $\begin{array}{l}\text { Nancuracy } \\
\left(\chi^{2}\right)\end{array}$ \\
\hline $\begin{array}{l}\text { Nanofibers/500 } \\
\text { ppm CO }\end{array}$ & 55.36 & 12.75 & $1.03 \mathrm{E}-7$ & 0.97 & $7.52 \mathrm{E} 4$ & $4.99 \mathrm{E}-5$ & 0.79 & $6.84 \mathrm{E}-4$ \\
\hline $\begin{array}{l}\text { Powders/Air } \\
\text { Powders/500 } \\
\text { ppm CO }\end{array}$ & 65.55 & 45.24 & $9.90 \mathrm{E}-8$ & 0.91 & $1.25 \mathrm{E} 5$ & $1.79 \mathrm{E}-5$ & 0.85 & $3.21 \mathrm{E}-4$ \\
\hline
\end{tabular}




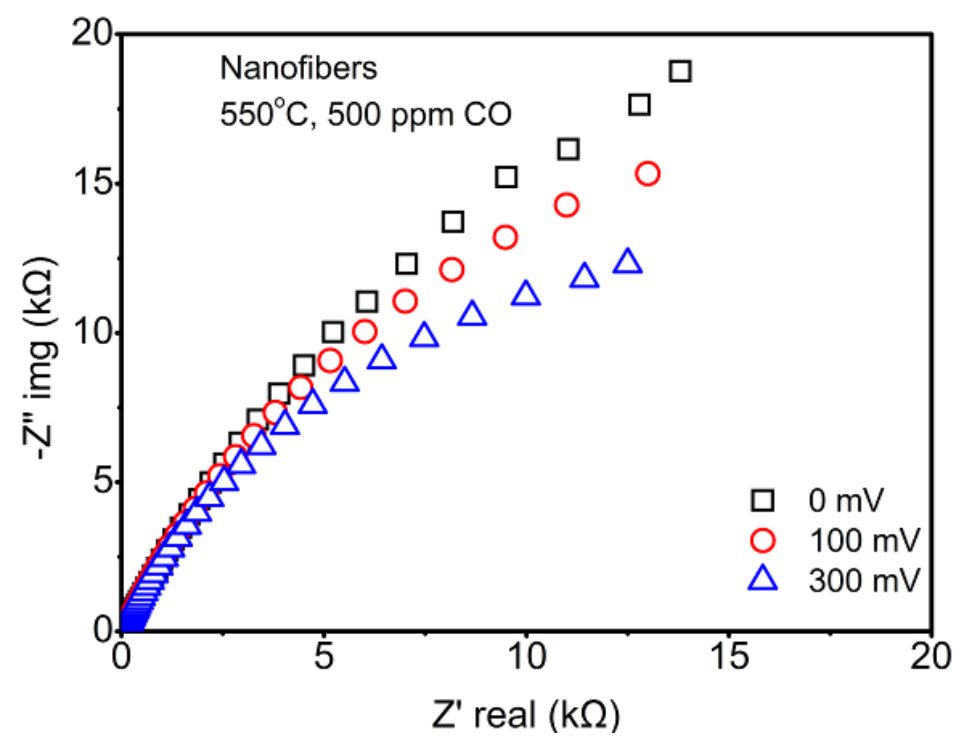

Figure 3.12: Impedance Nyquist curves of the nanofiber sensor at $550^{\circ} \mathrm{C}$ with $500 \mathrm{ppm} \mathrm{CO}$ taken at different DC bias

\subsection{Summary}

LSM nanofibers were successfully fabricated for the sensing electrode of electrochemical sensor to detect trace amounts of carbon monoxide at elevated temperatures. As compared to the micron-sized powders, the nanofibers had higher specific surface area, leading to an increased number of active reaction sites. The micro-structure being porous allowed better diffusion of gas to the active sites and the interconnected fibers network provided a continuous pathway for charge transport in the sensing electrode. Therefore the nanofiber electrode possessed better electro-catalytic activity towards $\mathrm{CO}$ oxidation and hence displayed better sensing properties in terms of limit of detection, sensitivity and response time compared to the micro-sized powder electrode samples. 


\section{Chapter 4: Conclusion and Future Work}

\subsection{Conclusions}

1. Electrospinning was successfully used to fabricate $\mathrm{La}_{0.8} \mathrm{Sr}_{0.2} \mathrm{MnO}_{3}$ nanofibers for the sensing electrode in a mixed-potential type gas sensor. These nanofibers were found to be stable even after sintering at $1050{ }^{\circ} \mathrm{C}$ and had good attachment to YSZ electrolyte.

2. The nanofibrous $\mathrm{La}_{0.8} \mathrm{Sr}_{0.2} \mathrm{MnO}_{3}$ sensing electrode was able to detect trace amounts of $\mathrm{CO}$ gas with fast response as compared to the bulk powders and showed a new approach for fabricating the sensing electrode in potentiometric type gas sensors for better response.

\subsection{Future work}

There is further scope in the present work.

1. Better performance of LSM nanofibers compared to their bulk counterparts has already been investigated. Therefore it is necessary to perform selectivity testings.

2. It is found the improvement in porosity resulted in better results. Therefore it is necessary to optimize the porosity. It is possible to enhance the sensor performance by adding highly active materials like $\mathrm{Pd}, \mathrm{Au}, \mathrm{Pt}$ etc. to further improve the sensing properties 


\section{References}

1. http://cfpub2.epa.gov/ncea/cfm/recordisplay.cfm?deid=65766. [Online]

2. http://www.epa.gov/airquality/carbonmonoxide/. [Online]

3. http://www.epa.gov/otaq/ld-hwy.htm\#regs. [Online]

4. Leonhard, V. Gas Sensors Based On Solid Ionic Conductors. [book auth.] Elsevier, Ansterdam M.Prudenziati. Thick Film Sensors, : Handbook of Sensors and Actuators. 1994, Vol. 1, pp. 261-288.

5. CDC. Unintentional non--fire-related carbon monoxide exposures in the United States, 2001-2003. . MMWR. 2005.

6. Unintentional carbon monoxide-Related deaths in the United States, 1979 through 1988.1991,. Cobb, C. and Cetzel, C.R. J. Am. Med. Assoc. , Vol. 266, pp. 659-663.

7. T. Grandke, J. Hesse,. Fundamentals and General Aspects. [ed.] W.H.Ko T. Grandke. Weinheim : s.n., 1989. Vol. 1.

8. Shimanoe, Noboru Yamazoe and Kengo. Science and Technology of Chemiresistor Gas sensors. [book auth.] Shiv K Gupta (eds.) Dinesh K Aswal. 2006.

9. High Temperature SAW Gas Sensor on Langasite. J. A. Thiele, M. Pereira da Cunha.

10. Surface acoustic wave gas sensors based on polyisobutylene and carbon nanotube composites. I. Sayago, M.J. Fernández, J.L. Fontecha, M.C. Horrillo, C. Vera, I. Obieta, I. Bustero. 2011, Sensors and Actuators B, Vol. 156, pp. 1-5.

11. The how and why of electronic hoses . Nagle, H.T., Gutierrez-Osuna, R. and Schiffman, S.S. 1998, IEEE Spectrum, Vol. 35, pp. 22-31.

12. A review of gas sensors employed in electronic nose applications . K. Arshak, E. Moore, G.M. Lyons, J. Harris and S. Clifford. 2004, Sensor Review, Vol. 24, pp. 181-198.

13. http://en.wikipedia.org/wiki/File:Methane-ir.png. [Online]

14. Non-Dispersive Infrared Analyzer (NDIR) Module,. NGA, Product Data Sheet. September 1999.

15. Air Pollution from Animal Wastes Determination of Malodors by Gas Chromatographic and Organoleptic Techniques. Burnett, WE. s.l. : ACS Publications, 1969 , Environmental Science \& Technology.

16. Critical review of nitrogen monoxide sensors for exhaust gases of lean burn engines. Francis Menil, Veronique Coillard, Claude Lucat. 2000, Sensors and Actuators B, Vol. 67, pp. 1-23. 
17. Understanding the fundamental principles of metal oxide based gas sensors; the example of CO sensing with SnO2 sensors in the presence of humidity. Weimar, N Barsan and U. 2003, J. Phys.: Condens. Matter, pp. R813-R839.

18. Semiconductor gas sensor for detecting NO and CO traces in ambient air of road traffic. Wiegleb, G. and Heitbaum, J. 1994, Sensors and Actuators B:Chemical, Vol. 117, pp. 93-99.

19. Porous Indium Oxide Nanotubes: Layer-by-Layer Assembly on Carbon-Nanotube Templates and Application for Room-Temperature NH3 Gas Sensor. y Ning Du, Hui Zhang, Bindi Chen, Xiangyang Ma, Zhihong Liu, Jianbo Wu, and Deren Yan. 2007, Adv. Mater., Vol. 19, pp. 1641-1645.

20. Improvement in $\mathrm{CO}$ sensing characteristics by decorating $\mathrm{ZnO}$ nanorod arrays with $\mathrm{Pd}$ nanoparticles and the related mechanisms. Chia-Ming Chang, Min-Hsiung Hon and Ing-Chi Leu. 20121, RSC Advances, Vol. 2, pp. 2469-2475.

21. Heywood, J.B. Internal Combustion Engine Fundamentals. s.1. : MacGraw Inc., 1988, Vol. 572.

22. Titania-Based Miniature Potentiometric Carbon Monoxide Gas Sensors with High Sensitivity”, 93 [3]. Jun-Young Park, Abdul-Majeed Azad, Sun-Ju Song and Eric D. Wachsman. 2010, Journal of the American Ceramic Society, Vol. 93 [3], pp. 742-749.

23. Ceria-electrolyte based mixed potential sensors for the detection of hydrocarbons and carbon monoxide. R. Mukundan, E.L. Brosha, D.R. Brown, F.H. Garzon. 1999, Electrochemical Solid-State Letters, Vol. 2 (12), pp. 412-414.

24. A new type of mixed potential sensor using a thick film of beta alumina. Lalauze $\mathbf{R}$, Visconte E, Montanaro L, Pijolat C. 1993, Sensors and Actuators B, Vols. 13-14, pp. 241-243.

25. Oxygen and carbon monoxide role on the electrical response of a non-Nernstian potentiometric gas sensor; proposition of a model. Guillet N, Lalauze R, Pijolat C. 2004, Sensors and Actuators B, Vol. 98, pp. 130-139.

26. Development of a gas sensor by thick film technology for automotive applications: choice of materials-realization of a prototype. C 21: Guillet N, Lalauze R, Viricelle JP, Pijolat C, Montanaro L. 2002, Mater Sci Eng , pp. 97-103.

27. Potentiometric Gas Sensors for Oxidic Gases. Noboru Yamazoe, Norio Miura. 1998, Journal of Electroceramics, pp. 243-255.

28. Thin solid state electrochemical gas sensors . Velasco. G, J.Ph. Schnell, M. Croset. 1981, Sensors and actuators, Vol. 2, pp. 371-384.

29. Advanced principles of sensors based on solid state ionics . W, Weppner. 1992, Material Science and Engineering B, Vol. 15, pp. 48-55. 
30. Solid-state electrochemical gas sensors . C. O. Park, J. W. Fergus, N. Miura, Jinsu Park and Angi Choi. 2009, Ionics, Vol. 15, pp. 261-284.

31. Solid-state potentiometric gas sensors-current status and future trends. P. Pasierb, M. Rekas. 2009, Journal of Solid State Electrochemistry, Vol. 13, pp. 3-25.

32. Progress in mixed-potential type devices based on solid electrolyte for sensing redox gases. Norio Miura, Geyu Lu, Noboru Yamazoe. 2000, Solid State Ionics, Vols. 136-137, pp. 533542 .

33. A review of electrolyte and electrode materials for high temperature electrochemical $\mathrm{CO} 2$ and SO2 gas sensors. Fergus, Jeffrey W. 2008, Sensors and Actuators B, Vol. 134, pp. 10341041.

34. Sensing mechanism of non-equilibrium solid-electrolyte-based chemical sensors. Fergus, Jeffrey W. 2011, Journal of Solid State Electrochemistry, Vol. 15, pp. 971-984.

35. . C, Wagner. 1943, Naturwissenschaften, Vol. Volume 31, pp. 265-268.

36. Measurements of galvanic cells involving solid electrolytes. . Kiukkola K, Wagner C. 1957, J Electrochem Soc, Vol. 104, pp. 379-387.

37. Zirconia-Based Potentiometric Sensors Using Metal Oxide Electrodes for Detection of Hydrocarbons. Takashi Hibino, Atsuko Hashimoto, Shiro Kakimoto, and Mitsuru Sano. 2001, Journal of The Electrochemical Society, Vol. 148 (1), pp. 1-5.

38. Planar electrochemical sensors based on tape-cast YSZ layers and oxide electrodes. Elisabetta Di Bartolomeo, Narin Kaabbuathong, Maria Luisa Grilli, Enrico Traversa. 2004, Solid State Ionics, Vol. 171, pp. 173-181.

39. Highly selective CO sensor using stabilized zirconia and a couple of oxide electrodes . $\mathbf{N}$. Miura, T. Raisen, G. Lu, N. Yamazoe. 1998, Sensors Actuators B, Vol. 47, pp. 84-91.

40. Solid-state mixed potential gas sensors: theory, experiments and challenges. Fernando $\mathbf{H}$. Garzon, Rangachary Mukundan, Eric L. Brosha. 2000, Solid State Ionics, Vols. 136-137, pp. 633-638.

41. Stabilized zirconia-based planar sensor using coupled oxide $(+A u)$ electrodes for highly selective $\mathrm{CO}$ detection. Sri A. Anggraini, Vladimir V. Plashnitsa, Perumal Elumalai, Michael Breedon, Norio Miura. 2011, Sensors and Actuators B, Vol. 160, pp. 1273-1281.

42. "Construction of Sensitive and Selective Zirconia-Based CO Sensors Using ZnCr2O4-Based Sensing Electrodes. Yuki Fujio, Vladimir V. Plashnitsa, Michael Breedon, and Norio Miura. 2012, Langmuir, Vol. 28, pp. 1638-1645.

43. Mixed-potential-type zirconia-based NO2 sensor with high-performance three-phase boundary. Xishuang Liang, Shiqi Yang, Jianguo Li, Han Zhang, Quan Diao, Wan Zhao, Geyu Lu. 2011, Sensors and Actuators B, Vol. 158, pp. 1-8. 
44. La2CuO4 sensing electrode configuration influence on sensitivity and selectivity for a multifuntional potentiometric gas sensor. Eric R. Macam, Briggs M. White, Laure Chevallier, Frederick M. Van Assche, Bryan M. Blackburn, Elisabetta Di Bartolomeo, Enrico Traversa, Eric D. Wachsman. 2011, Sensors and Actuators B, Vol. 160, pp. 957-963.

45. Tunable NO2-Sensing Characteristics of YSZ-Based Mixed-Potential-Type Sensor Using

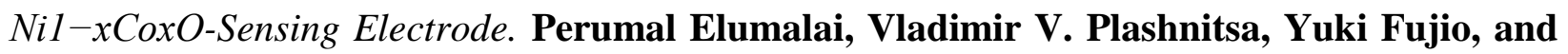
Norio Miura. 2009, Journal of The Electrochemical Society, Vol. 156 (9), pp. j288-j293.

46. Stabilization of sensing performance for mixed-potential-type zirconia-based hydrocarbon sensor. Yuki Fujio, Vladimir V. Plashnitsa, Perumal Elumalai, Norio Miura. 2011, Talanta, pp. 575-581.

47. YSZ-based Sensor Using NiO Sensing Electrode for Detection of Volatile Organic Compounds in ppb Level. Tomoaki Sato, Vladimir V. Plashnitsa, Masahiro Utiyama, and Norio Miura. 2011, Journal of The Electrochemical Society, Vol. 158(6), pp. j175-j178.

48. Sensing behavior of YSZ-based amperometric NO2 sensors consisting of Mn-based reference-electrode and In2O3 sensing-electrode. Han Jin, Michael Breedon, Norio Miura. 2012, Talanta, Vol. 88, pp. 318-323.

49. Influence of sensing electrode and electrolyte on performance of potentiometric mixedpotential gas sensors. Xiaogan Li, Girish M. Kale. 2007, Sensors and Actuators B, Vol. 123, pp. 254-261.

50. Solid oxide amperometric $C O$ sensor for monitoring exhaust gas from water heater. Tatsumi Ishihara, Phawachalotorn Armonat, Rie Kadowaki and Oravan Sanguanruang. 2010, sensors and materials, Vol. 22 (4), pp. 183-192.

51. Electrochemical investigations on multi-metallic electrodes for amperometric NO gas sensors. P. Schmidt-Zhang, W. Zhang, F. Gerlach, K. Ahlborn, U. Guth. 2005, Sensors and Actuators B, Vol. 108, pp. 797-802.

52. Zirconia-based amperometric sensor using $\mathrm{ZnO}$ sensing-electrode for selective detection of propene. Taro Ueda, Vladimir V. Plashnitsa, Mitsunobu Nakatou, Norio Miura. 2007, Electrochemistry Communications, Vol. 9, pp. 197-200.

53. Impedance-metric Pt/YSZ/Au-Ga2O3 sensor for CO detection at high temperature. Nianqiang Wu, Zheng Chen, Jianhui Xu, Minking Chyu, Scott X. Mao. 2005, Sensors and Actuators B, Vol. 110, pp. 49-53.

54. Impedance-based total-NOx sensor using stabilized zirconia and $\mathrm{ZnCr} 2 \mathrm{O} 4$ sensing electrode operating at high temperature. N. Miura, M. Nakatou, S. Zhuiykov. 2002, Electrochemistry Communications, Vol. 4, pp. 284-287. 
55. Impedancemetric gas sensor based on zirconia solid electrolyte and oxide sensing electrode for detecting total NOx at high temperature. Norio Miura, Mitsunobu Nakatou, Serge Zhuiykov. 2003, Sensors and Actuators B, Vol. 93, pp. 221-228.

56. Detection of combustible hydrogen-containing gases by using impedancemetric zirconiabased water-vapor sensor. Mitsunobu Nakatou, Norio Miura. 2005, Solid State Ionics, Vol. 176, pp. 2511-2515.

57. Impedancemetric sensor based on YSZ and In2O3 for detection of low concentrations of water vapor at high temperature. Mitsunobu Nakatou, Norio Miura. 2004, Electrochemistry Communications, Vol. 6, pp. 995-998.

58. Detection of propene by using new-type impedancemetric zirconia based sensor attached with oxide sensing-electrode", 120,. Mitsunobu Nakatou, Norio Miura. 2006, Sensors and Actuators B, Vol. 120, pp. 57-62.

59. Supramolecular and polymeric structures for gas sensors. . Gopel, W. 1995, Sens. Actuat. B-Chem, Vol. 24, pp. 17-32.

60. Nitrogen oxides-sensing characteristics of WO3-based nanocrystalline thick film gas sensor. Lee, D., et al., et al. 1999, Sens. Actuat. B-Chem, Vol. 60, pp. 57-63.

61. Gas sensors based on nanostructured materials. Giselle Jimenez-Cadena, Jordi Riu and F. Xavier Rius. 2007, Analyst, Vol. 132, pp. 1083-1099.

62. Gas Sensors Based on Electrospun Nanofibers . Ding B, Wang M, Yu J Y and Sun G. 2009, Sensors, Vol. 9, p. 1609.

63. A lactate electrochemical biosensor with a titanate nanotube as direct electron transfer promoter. Yang M, Wang J, Li H Q, Zheng J G and Wu N Q. 2008, Nanotechnology, Vol. 19(7).

64. Sol-gel derived La0.6Sr0.4CoO3 nanoparticles, nanotubes, nanowires and thin films. J. Wang, A. Manivannan, N. Q. Wu. 2008, Thin Solid Films, Vol. 517, pp. 582-587.

65. Shape-enhanced photocatalytic activity of single-crystalline anatase TiO2 (101) nanobelts. N. Q. Wu, J. Wang, D. Tafen, H. Wang., J.-G. Zheng, J. P. Lewis, X. Liu, S. S. Leonard, A. Manivannan. 2010, Journal of American Chemical Society, Vol. 132, pp. 6679-6685.

66. Tuning the charge transfer property of PbS-quantum dot/TiO2-nanobelt nanohybrids via quantum confinement. D. Wang, H. Zhao, N. Q. Wu, A. El Khakani, D. Ma. 2010, Journal of Physical Chemistry Letters, Vol. 1(7), pp. 1030-1035.

67. Nanofiber scaffold for cathode of solid oxide fuel cell. Zhi M J, Mariani N, Germen R, Gerdes K and Wu N Q. 2011 , Energy \& Environmental Science, Vol. 4, p. 417.

68. An intermediate temperature solid oxide fuel cell with electrospun nanofiber cathode. M. Zhi, S. Lee, N. Miller, N. H. Menzler and N. Q. Wu. 2012, Energy \& Environmental Science. 
69. Porous CuO-ZnO Nanocomposite for Sensing Electrode of High-Temperature CO SolidState Electrochemical Sensor. Wu N Q, Zhao M H, Zheng J G, Jiang C B, Myers B, Li S X, Chyu M K and Mao S X. 2005, Nanotechnology, Vol. 16, p. 2878.

70. AC impedance characterization of ZnO-nanobelt/Pd Schottky contact in ammonia. Xu J, Wu N Q, Jiang C, Zhao M, Li J, Wei Y and Mao S X. 2006, Smal, Vol. 2, pp. 1458-1461.

71. Gas sensing properties of $\mathrm{MoO} 3$ nanorods to $\mathrm{CO}$ and $\mathrm{CH} 3 \mathrm{OH}$. Comini E, Yubao L, Brando Y and Sberveglieri G. 2005, Chemical Physics Letters, Vol. 407, p. 368.

72. Nano-structured perovskite oxide electrodes for planar electrochemical sensors using tape casted YSZ layers. Bartolomeo E D, Kaabbuathong N, D'Epifanio A, Grilli M L, Traversa E, Aono H and Sadaoka Y. 2004, Journal of the European Ceramic Society, Vol. 24, p. 1187.

73. Application of nano-crystalline porous tin oxide thin film for $C O$ sensing. Jin, Z., et al., et al. 1998, Sens. Actuat. B-Chem, Vol. 52, pp. 188-194.

74. Gas sensing properties of nano-ZnO prepared by arc plasma method. . Dong, L., Cui, Z. and Zhang, Z. 1997, Nanostruct. Mater., Vol. 8, pp. 815-823.

75. Nanometer diameter fibers of polymer, produced by electrospinning. Reneker, D. and Chun, I. 1996, Nanotechnology, Vol. 7, pp. 216-223.

76. Electrospinning process and applications of electrospun fibers. Doshi, J. and Reneker, D. 1995, J. Electrost, Vol. 35, pp. 151-160.

77. Electrospinning processed nanofibrous TiO2 membranes for photovoltaic applications. . Onozuka, K., et al., et al. 2006, Nanotechnology, Vol. 17, pp. 1026-1031.

78. Nanoprocessing of polymers: applications in medicine, sensors, catalysis, photonics. Dersch, R., et al., et al. 2005, Polym. Advan. Technol., pp. 276-282.

79. Effects of humidity, temperature, and nanofibers on drop coalescence in glass fiber media. Hajra, M., Mehta, K. and Chase, G. 2003, Sep. Purif. Technol, Vol. 30, pp. 79-88.

80. Electrospun nanofibrous membranes coated quartz crystal microbalance as gas sensor for NH3 detection. Ding, B., et al., et al. 2004, Sens. Actuat. B-Chem, Vol. 101, pp. 373-380.

81. Electrospun nanofibrous polyelectrolytes membranes as high sensitive coatings for QCMbased gas sensors. Ding, B., et al., et al. s.1.: Nova Science Publishers, 2006, In Nanotechnology at the Leading Edge, pp. 1-28.

82. Electrospun polymer composite fiber arrays for the detection and identification of volatile organic compounds. Kessick, R. and Tepper, G. 2006, Sens. Actuat. B-Chem, Vol. 117, pp. 205-210.

83. Fabrication and ethanol-sensing properties of micro gas sensor based on electrospun $\mathrm{SnO} 2$ nanofibers. . Zhang, Y., et al., et al. 2008, Sens. Actuat. B-Chem, Vol. 132, pp. 67-73. 
84. Processing-microstructure-properties correlation of ultrasensitive gas sensors produced by electrospinning. Landau, O., Rothschild, A. and Zussman, E. 2009, Chem. Mater., Vol. 21, pp. 9-11.

85. Ultrasensitive chemiresistors based on electrospun TiO2 nanofibers. Kim, I., et al., et al. 2006, Nano Lett., Vol. 6, pp. 2009-2013.

86. Electrospun nanocomposite fiber mats as gas sensors. Luoh, R, Hahn, H.T. 2006, Composites. Sci. Techno, Vol. 66, pp. 2436-2441.

87. Individually-addressed large-scale patterning of conducting polymers by localized electric field, . M. Su, L. Fu, N. Q. Wu, M. Aslam, and V. P. Dravid. 2004, Applied Physics Letters, Vol. 84(5), pp. 828-830.

88. Dip-pen nanopatterning of photosensitive conducting polymer using a monomer ink. M. Su, M. Aslam, L. Fu, N. Q. Wu, and V. P. Dravid. 2004, Appl. Phys. Lett, Vol. 84(21) , pp. 42004202.

89. Optimum design of sensor arrays via simulation-based multivariate calibration. Z. Geng, F. Yang, N. Q. Wu. 2011, Sensors \& Actuators B, Vol. 156, pp. 854-862.

90. Fabrication and Characterization of Metal Oxide Nanowire Sensors . Z, Shen G. 2008, Recent Patents on Nanotechnology, Vol. 2, p. 160.

91. A highly selective CO sensor using LaMnO3 electrode-attached zirconia galvanic cell. T, Sorita R and Kowano. 1997, Sensors and Actuators B, Vol. 40, pp. 29-32.

92. A highly selective CO sensor: screening of electrode materials. T, Sorita $\mathbf{R}$ and Kowano. 1996, Sensors and Actuators B, Vols. 35-36, pp. 274-277.

93. Gas sensing behavior of modified LaMnO3 ceramic. J, Pawar M. 2007, Journal of Optoelectronics and Advanced Materials, Vol. 9, p. 3785.

94. Solid-state mixed potential gas sensors: theory, experiments and challenges. Fernando $\mathbf{H}$. Garzon, Rangachary Mukundan, Eric L. Brosha. 2000, Solid State Ionics, Vols. 136-137, pp. 633-638.

95. Planar Impedance-Metric NOX Sensor with NiO Sensing Electrode for High Temperature Applications. B, Stranzenbach M and Saruhan. 2007. Solid-State Sensors-Actuators and Microsystems Conference.

96. Planar impedance-metric NOx-sensor with spinel-type SE for high temperature applications. M. Stranzenbach, E. Gramckow, B. Saruhan. 2007, Sensors and Actuators B, Vol. 127, p. 224.

97. Porous Indium Oxide Nanotubes: Layer-by-Layer Assembly on Carbon-Nanotube Templates and Application for Room-Temperature NH3 Gas Sensor. Y Ning Du, Hui Zhang, Bindi Chen, 
Xiangyang Ma, Zhihong Liu, Jianbo Wu, and Deren Yan. 2007, Advanced Materials, Vol. 19, pp. 1641-1645.

98. Infrared gas sensor. Changqing Li, and Zhenzhen Yin. 2010, Proceedings of the Third International Symposium on Electronic Commerce and Security Workshops(ISECS '10), Vols. 29-31, pp. 101-104.

99. Ceramic electrolytes and electrochemical sensors. 38:4639-4660 special issue on. Park CO, Akbar SA, Weppner W. 2003, J Mater Sci .

100. Solid electrolyte based sensors for the measurement of $C O$ and hydrocarbon gases. Fergus, Jeffrey W. 2007, Sensors and Actuators B, Vol. 122, pp. 683-693.

101. A Mixed-Potential Sensor Based on a Ce0.8Gd0.2O1.9 Electrolyte and Platinum and Gold Electrodes. R. Mukundan, E. L. Brosha, D. R. Brown, and F. H. Garzon. 2000, Journal of The Electrochemical Society, Vol. 147 (4), pp. 1583-1588.

102. Ceria-Electrolyte based mixed potential sensors for the detection of hydrocarbons and carbonmonoxide. R. Mukundan, Eric L. Brosha, David R. Brown, Fernando H. Garzon. 1999, Electrochemical and solid-state letters, Vol. 2(8), pp. 412-414.

103. Meredith, C.T. . Correction: Comroe and Dripps revisited. 1988, 296, 110. Brit. Med. J. . 1988, Vol. 296, p. 110.

104. Risk and protective factors for fires, burns, and carbon monoxide poisoning in U.S. households. Runyan, C.C., et al., et al. 2005, Am. J. Prev. Med, Vols. 28,, pp. 102-108.

105. A. Carbon monoxide poisoning: A review for clinicians. Med., J. Emer. 1999, J. Emer. Med., Vol. 17, pp. 87-93.

106. Weinheim. Fundamentals and General Aspects,. [book auth.] W. H. Ko T. Grandke. Sensors . s.l. : VCH-Verlag, , 1989.

107. CO/HC sensors based on thin films of LaCoO3 and La0.8Sr0.2CoO3- $\delta$ metal oxides. Eric L. Brosha, R. Mukundan, David R. Brown, Fernando H. Garzon, J.H. Visser, M. Zanini, Z. Zhou, E.M. Logothetis. 2000, Sensors and Actuators B, Vol. 69, pp. 171-182. 